\title{
Economic policy uncertainty and energy production in China
}

\author{
Wei Wei ${ }^{1} \cdot$ Haiqing $\mathrm{Hu}^{1} \cdot$ Chun-Ping Chang ${ }^{2}$ (D) \\ Received: 6 April 2021 / Accepted: 10 May 2021 / Published online: 25 May 2021 \\ (C) The Author(s), under exclusive licence to Springer-Verlag GmbH Germany, part of Springer Nature 2021
}

\begin{abstract}
Owing to economics are usually linked with energy production, economic policy may have an instantaneous adjustment according to the current monetary, financial, cultural circumstances. This research thus investigates the dynamic co-movement as well as cointegration relationships between economic policy uncertainty (EPU) and disparate energy productions, i.e., Chinese coal, natural gas, crude oil, electricity as well as renewable energy, during the period from January 1995 to October 2019 in China. We compare the two EPU indices and make empirical and robust analysis to get more evidence for the time-varying comovement between energy production and EPU. The empirical results show that there are stationary properties and cointegration relationships between energy production and EPU. By utilizing wavelet co-movement analysis in the time-frequency domain, our results show a significant positive co-movement among disparate energy productions and EPU at high frequencies, i.e., in the short term, but weaker co-movement at low frequencies, i.e., in the long term. Hence, the phase-difference series are mostly around the zero line, implying the variables behave to the dynamics of the co-movement with positive causality. Policy recommendations are offered in accordance with our finding.
\end{abstract}

Keywords Economic policy uncertainty; · Energy production; · Wavelet co-movement; · Phase-difference; · Time-frequency domain

JEL Classifications C32 $\cdot \mathrm{C} 51 \cdot \mathrm{Q} 43 \cdot \mathrm{G} 14$

\section{Introduction}

Accompanied by changes in government economic policy, energy industry capacity also needs to be adjusted. Economic policy uncertainty is currently greater in magnitude and more important in terms of its impacts than ever before (Baker and Bloom 2013), as rapid growth in industrial and urban economies largely depends on energy production. Contrarily, energy resources are distributed unequally, and economic policy uncertainty with high imparity at the same time brings challenges for achieving various targets (Herrerias et al. 2013). Compared to energy consumption, the fluctuation of energy production not only

Responsible Editor: Roula Inglesi-Lotz

Chun-Ping Chang

cpchang@g2.usc.edu.tw

1 School of Economic and Management, Xi' an University of Technology, Xi'an, Shaanxi, China

2 Shih Chien University, Kaohsiung Campus, Kaohsiung, Taiwan influences enterprises' development, but also residents' lives. A strong understanding of energy production that contains coal, natural gas, crude oil, electricity, and renewables is thus directly connected with effective future energy policy making (Barro et al. 2011; Song and Zheng 2012). Because an economic subject cannot forecast accurately whether, how, and when the government will adjust the relative policy, energy production, as a vital driver of economic development, has to be changed through economic policy uncertainty. An examination into the nexus of energy production and economic policy uncertainty thus contributes to the existing literature and presents important policy implications to authorities.

With its opening up reforms and policies, China as a rapidly developing emerging economy has witnessed high-speed growth and remarkable achievements. However, such speedy and high economic growth rates have brought about extreme energy consumption and pollution levels (Xiao et al. 2018; Pan et al. 2019). Environmental sustainability, climate change, and global warming doubtlessly have become serious issues and drawn increasing public attention. The China government 
thus proposed the goal of constructing an environmentfriendly society that aims to save resources (Ma 2015; Bloch et al. 2012). ${ }^{1}$ However, various goals have brought considerable shocks to the whole energy industry chain, particularly when most economic activities are all dependent on adequate energy supply. Hence, we utilize China's disparate energy productions (i.e., oil, coal, natural gas, electricity, and even renewable energy) as the research subject, because they are the main forms of energy consumption in China, and only a few research studies focus on energy in such detail, and even fewer place attention on how economic policy uncertainty can shock disparate energy productions. Thus, we choose the main energy forms in China to present some important findings.

The purposes of this paper are to examine what challenges uncertainties of economic policy will bring to Chinese energy production, does a cointegration relationship exist in the trends of energy production and EPU? And what kinds of time series have a role during long- and short-run periods? We analyze energy production via datapoints on coal (hereafter, COAL), crude oil (hereafter, OIL), natural gas (hereafter, GAS), electricity (hereafter, ELEC) and renewable energy (hereafter, RENEW), while for EPU depending on the South China Morning Post (hereafter, EPU SCMP $_{\text {), we utilize }}$ EPU $_{\text {SCMP }}$ presented by Baker et al. (2016). The time period contains from January 1995 to October 2019 for China, so that we can examine the dynamic co-movement as well as cointegration relationship via both time and frequency domains. The empirical procedure starts by investigations of COAL, GAS, OIL, ELEC, RENEW as well as EPU SCMP $_{\text {for }}$ unit roots with structure breaks. After providing evidence of the variables' stationary property, we perform cointegration analysis with structural breaks to get cointegration relationships among the variables. Next, we utilize wavelet comovement analysis to examine the strength of the dynamic co-movement between disaggregate energy production and $\mathrm{EPU}_{\mathrm{SCMP}}$ and employ phase-difference analysis to present the time-varying positive or negative causal relationships among variables. Applying these techniques, we present suitable policy implications for authorities, energy producers, investors, and even individual households.

From the global financial crisis in 2008, economic policy uncertainty has become a flourishing topic. It refers to monetary, fiscal, and regulatory policy uncertainties from economic changes (Bloom 2009; Bachmann et al. 2013; Baker et al. 2016; Davis et al. 2019). Baker et al., (2016) has provided the economic policy uncertainty index (hereafter, EPU), which is constructed on an automated search process for

\footnotetext{
${ }^{1}$ Energy Information Administration (EIA 2016) asserted that as China is responsible for nearly $50 \%$ of global coal consumption and $25 \%$ of global carbon dioxide emission, it has particularly drawn up a target of decreasing emissions per unit of GDP by $60-65 \%$ basing on the 2005 level and raising the clean energy resource percentage within main energy consumption to $20 \%$.
}

economic activities by tracing frequency terms, like economic policy-, uncertainty-, and regulation-related words, through major newspapers. Accordingly, there are two popular Chinese EPU indices presented by Baker et al. (2016) and Davis et al. (2019): the China EPU index relying on the South China Morning Post $\left(\mathrm{EPU}_{\mathrm{SCMP}}\right)$ and China EPU Indices based on Mainland Papers $\left(\mathrm{EPU}_{\mathrm{MP}}\right)$; i.e., Renmin Daily and Guangming Daily are widely utilized in current research. Newspapers' sources, frequency terms and time spans are the major differences between the two indices (see the details in Appendix 1). We also note that China's EPU includes the impacts of economic policies on investment, consumption, and employment of enterprises and individuals, on the macroeconomy, capital, energy markets, etc. The index stems from three major uncertain origins: the occurrence frequency of news concerning Chinese monetary and fiscal policies, the number of relevant tax provisions, as well as forecasting disagreement about future government purchases and inflation.

EPU can theoretically be linked to energy production through multiple channels. Primarily, the adjustments of economic policies can influence a country's economic activities, further bring about the fluctuation of energy market (Khandokar and Serletis 2018). Increasing EPU may change investors decisions, adjust the demand-supply curve in energy markets, and shift industrial demand and consumer for energy usage. Hamilton (1983) presents that energy consumption and EPU may keep a tightly coupled relationship, through changes of energy prices resulting in energy market's demand and supply fluctuations, further a negative influence will lead to macroeconomics. ${ }^{2}$ There is also a positive opinion between EPU and energy production in China. ${ }^{3}$ Some potential reasons arise. First, Uncertainties of economic policy have an influence on China's energy markets, following the imbalance of energy demand and supply, further energy price will increase. This is because while the expectations occurred, energy investors and consumers would worry about more uncertainties, bargain price and energy output costs will increase in the near future (Mahardika et al. 2019; Jaiswal and Kant 2018). Next, investors and consumers will adjust their purchase decisions and energy consumption strategies (Hsu et al. 2017; Hafezalkotob 2018). Practically speaking, most investors and consumers will buy more energy products, to avoid risks and future increase of energy market, then energy demand will

\footnotetext{
${ }^{2}$ Such as economic activities, which can influence investors and consumers on energy utilization (Hamilton 1983; Aloui et al. 2016; Olanipekun et al. 2019).

${ }^{3}$ Different countries have their own characteristics, numerous heterogeneity factors, for example, culture, habits and customs, energy reserve condition and political environment etc., will lead to energy imbalance then result in fluctuation of economic policy, which bring about many uncertainties components of economic policy (Li and Lin 2016). Characterized by large population and shortage of resources, China's energy market has its special background (Fang and Chen 2017; Jiang et al. 2019).
} 
raise and following the increasing energy price, subsequently more energy productions is needed by market (Sheu 2011). Second, once uncertainties of economic policy are noticed by the government through fluctuation of energy price, the government may implement more monetary and fiscal policies for energy markets to weaken uncertain risks. However, an excessive policy intervention would bring about higher energy price, then more increasing in energy demand and production, further greater volatility in energy market (Zhang and Yousaf 2020).

Why causality may run from energy production to EPU? Three channels we propose can achieve the transmission, i.e., real output, income transfer, potential output and so on. First, as the change of energy price will directly affect energy production and then affect a country's output, labor supply and demand, total supply and demand imbalance, resulting in price changes and other economic fluctuations, we call the phenomenon real output effect (Abaidoo 2019). Second, the theory on income transfer holds that fluctuations in energy markets will change energy production, and lead to a shift in income between energy-importing and exporting countries, which will lead to changes of bilateral energy consumption as well as aggregate demand in turn, then bring about business volatility (Shah et al. 2018). Finally, we suppose that energy products and other capitals are complementary in production. When the energy market fluctuates, it will not only affect the supply and demand of energy products, but also affect the usage of other capital, resulting in a change in production curve and potential output (Gupta and Krishnamurti 2018). Since the shale revolution, Arora and Lieskovsky (2014) discuss that economic performance is impacted by energy market, and a long-run nexus is existed in economic growth and energy consumption (Sari et al. 2008; Apergis and Payne 2010). Overall, the nexus of overall economy and energy production is symmetrical and co-shifting. In general, the nexus among EPU and disparate energy productions are blurry, detailed and rigorous researches are demanded.

Previous research of energy production always ignores a vital perspective of frequency domain, from which literature can gain significant and momentous information when examining energy production. Energy production is generated from a procedure consisting of various factors managing at different frequencies (Tiwari et al. 2013; Barro et al. 2016). For one thing, spot and future characteristics in the energy market bring forth essential changes to the time domain. The interaction between various time horizons and term objectives constitutes the whole energy market, such that market heterogeneity brings about disparate dealing frequencies. For another thing, disparate energy productions can be influenced by components that operate at various time scales, which may result in diverse underlying cycles in the energy production. Moreover, the relationship between different variables leads to diverse results at various frequencies (Benhmad 2012; You et al. 2017). Dvidinging data into disparate time frequencies may also bring about important perspectives for heterogenous factors under various time horizons so as to availably operate the asset portfolio (Chang and Lee 2015). Therefore, by considering the time-varying and frequency-varying relationship between EPU and energy production at the same time, one can realize more accurate production predictions for authorities and other market participants.

Why should we consider structural breaks? External shocks, such as the 1997 Asian financial crisis, 2001 China entering World Trade Organization 2002 global financial crisis, the decrease in world trade in 2014, and even the COVID19 pandemic, have considerable influences on the time series of our sample period. The equilibrium trend of the variables may be broken due to external shocks from the outside world, and historical shocks should take into account when examining the cointegration relationship. The potential reasons are presented here. As national or international energy events bring external shocks, which shocks always affect energy development, so structural breaks should take into account during the energy trend, because neglecting structural breaks will result in biased and spurious findings, as well as inaccurate and ambiguous references for policymakers' energy decisions, energy investing, and consuming (Linn and Muehlenbachsn 2018; Shahbaz et al. 2014). Hence, investigating the long-run trends with endogenou break locations among energy production and EPU can significantly strengthen research efficiency and accuracy, also bring about more precise findings on the variables' mean-reverting behaviors. We can also identify the time points of the momentous historical events through endogenous breaks, and next examine the cointegrated relationship among disparate energy productions as well as EPU more accurately (Chang and Lee 2008; Stern et al. 2005; Friedl and Getzner 2003). Disparate shocks should take into account, because momentous issues may present during the time series covering several decades (Chang et al. 2013; Dai et al. 2017; Hu et al. 2019).

Our main contributions are as follows. First, we are a pioneering research that examines the dynamic comovement among EPU and China's traditional and renewable energy productions, utilizing a time series sample as well as a panel dataset. We not only fill a gap in the literature adopting high and low frequencies' co-movement of EPU and energy production in China, but also enhance the research concerning disparate energy productions and EPU. Second, as energy production and policy formulation can be influenced by external changes, we thus add structural breaks into our investigation to bring forth more accurate results and identify structural breaks to predict EPU and energy production long-run trends. In addition, advanced analysis of wavelet co-movement is adopted, which considers variables' information at both low and high frequencies, to obtain evidence of co-movement between China's traditional and renewable energy productions 
and EPU. Moreover, the results of phase differences show causal and lead-lag relations in our series. It is hence significant to take these trends into account as co-movement in EPU, which can provide reference for policy directions. Furthermore, we apply a new EPU index proposed by Davis et al. (2019), using more newspaper sources in China, as one of the robust analyses and present further dynamic comovement evidence. Finally, the answers herein should present abundant policy implications for in-depth insight into the co-movement among disparate energy productions and EPU as well as energy conservation, which can help set executable emission reducing goals for sustainable economic and energy developing progress.

The remainder of our paper runs as follows. The "An overview of China's energy production and economic policy uncertainty" section provides the disaggregate energy profile in

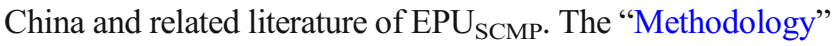
section briefly introduces our econometric approaches adopted and finally illuminates the dataset as well as fundamental descriptive statistics analysis among disparate energy

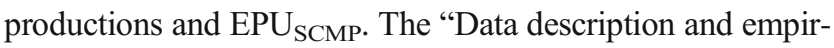
ical result" section examines our experimental findings and policy implications. The main conclusions of our examination are summarized in the "Concluding remarks" section.

\section{An overview of China's energy production and economic policy uncertainty}

China owns the most populous country and rapid economic growth in the world. Its energy demand and consumption have increased due to its high-speed modernizing economy and sizeable industrialization. EIA (2015) reports that China became the largest global energy consumption market in 2011 and the global highest coal producer and consumer, just behind the US. This section presents an overview of the disparate energy products, i.e., coal, natural gas, crude oil, electricity and renewable energy) for the period during January 1995 to October 2019.

We first introduce the profile of coal in China. In the past few decades, Chinese coal consumption has greatly affected its air quality, making it the main source accelerating the global warming process. In 2015, the global amount (BP 2016) asserted that China's coal consumption and carbon dioxide emissions took over $47.7 \%$ and $27.2 \%$, respectively. The large amount of coal consumption brings about greenhouse gas emission and other inevitable environmental issues. The literature has presented that coal burning occupied the major resources of China's regional hazy pollution (Zhang et al. 2013; Xie et al. 2015). In fact, China's coal consumption accounts for $62 \%$ among all energy use, and which can significantly influence the environment (Edenhofer 2015). Qin et al. (2017) asserted that coal will remain the most credible and safest energy resource for China during the following 20 years. As China's economy has rapidly developed, its energy supply will continually increase, but eventually become inadequate (Chen and Xu 2010). EPU will accelerate the pace of development of coal.

Despite coal's dominant position as an energy resource, they are also necessary of oil and petroleum productions for energy supply in China. The market share of oil among entire energy consumption peaked at $22 \%$ in 2000 , and after that, the growth of oil consumption has slowed down, likely due to global financial crisis shocks, economic downturns, and the government's policy adjustments of reducing capacity overbuilding as well as excessive investing in pollution-intensive energy industries (Fang and Chen 2017). As the second heaviest country depleting oil in the world just behind the U.S., China largely depends on oil imports (EIA 2016), while keeps searching for new energy resources around its country. Whether and how policy uncertainty factors will affect oil are important questions for China's steady progress in oil development.

Regarded as a cleaner energy resource in China, rapid growth has already been shown of natural gas development. As it not only decreases environmental pollutants and greenhouse gas emissions, but also owns the potential for transitioning into $100 \%$ renewable energy resource, ${ }^{4}$ reserves, and deliveries in the forecasting future (Wang and Lin 2017; Kinnon et al. 2018). In accordance with the 13th Five-Year Plan for Natural Gas Development, by 2020, natural gas consumption can attain 3.6 trillion cubic meters and account for $8.3-10 \%$ of primary energy. However, many problems exist in natural gas industry development of China. For instance, seasonal surges in natural gas demand are attributed to augmented heating demand in the winters of 2009 and 2017, which then brought about a massive-scale shortcoming of China's natural gas supply (Fang and Chen 2017). In order to deal with this supply-demand problem, the government has taken actions to restrict natural gas and the measures have been implemented in Shanxi, Henan, as well as Shandong. The literature implies that China's natural gas cannot become regular quickly enough to fit this problem in demand, which will result in a greater reliance upon imports and increasing swinging of the supply of natural gas (Chen et al. 2018a; Tang et al. 2015). Precisely recognizing the fluctuations in China's consumption of natural gas, particularly EPU, is essential for the scientific establishment of natural gas.

Since China is an emerging economy with rapidly industrialized, electricity is one of the main energy resources for supporting the country's economic and social developments. Electricity is an important infrastructural component that intensifies production efficiency, encourages business activity, and promotes life quality via the intermediary of products and

\footnotetext{
${ }^{4}$ Renewable fuel here implies biogas, renewable hydrogen, and so on.
} 
services. In accordance with the World Energy Issues Monitor from the World Energy Council (2018), electricity storage, which is relevant to electricity consumption, greatly affects energy transition in economies. Large-scale electricity consumption always incurs air pollution (Wei et al. 2018; Tong et al. 2018), water shortages (Zhang et al. 2018), greenhouse gas emissions (Wang and Lin 2017; Zhou et al. 2019), and other issues of environmental pollution (Oberschelp et al. 2019). Under the context, in 2016, the China's 13th Fiveyear Plan forecasts total electricity consumption at 6.8 to 7.2 trillion kWh by 2020 (Zhang et al. 2020). Therefore, it is essential to take EPU into account when evaluating electricity consumption research, because the relationship between ELEC and EPU is a vital issue for China, particularly to benchmark future goals (Wu et al. 2019).

Following the implementation of China's Belt and Road Initiative, reducing $\mathrm{CO}_{2}$ emissions and local air pollution has become an essential policy goal, and the China government is aiming to quickly transform to lower carbon emissions by exploiting energy skills as well as renewable techniques. China has promoted the generation capacity of renewable resource using 59.96 million kilowatts, which has taken over $69 \%$ of its newly installed capacity in the first three quarters of 2018. The International Energy Agency (IEA 2018) reported that the consumption of renewable resources occupied $11.8 \%$ of total energy consumption, and in the near future China will take over as the world's largest renewable resource consuming country. Renewable energy will gradually play a more important role in the low carbon target of China and even in the world energy systems in the coming decades. The decision-making actions of renewable energy subjects can be influenced by the adjustments of economic policy, resulting in more careful and cautious decisions being made under high uncertainty. Additionally, China's 13th Five-Year Plan for Renewable Energy Development notes that the world will finally enter a new era with a more sustainable and cleaner society dominated by renewable energy. As the uncertainties over economic policy increase rapidly, China's economic activities will be affected, and its implementation of renewable energy may be shocked by economic fluctuations. What influences will arise is not certain, and so we shall investigate the nexus between renewable energy production and EPU in the following content.

Following the recent global financial crisis and partisan policy disputes around the world, rising attention is focusing on uncertain policies principally connected to economic volatilities and energy development decisions (Baker et al. 2016). Uncertain events, such as increasing unemployment rates, income inequality, large area migration, and energy price fluctuations, have further complicated economies' growth path. Policy uncertainties have always played a primary part contributing to economic outcomes, since countries that are currently undergoing policy uncertainties provide evidence of their sluggish economic growth. For instance, since 2014 China has called for a sweeping energy evolution, placing top priority on environmental targets and clean energy deployment. New forms of energy policy promotion have brought adjustments to the structure of energy markets. Energy resources, which are always regarded as the vital drivers of economic growth, are also important components affecting a country's security and development (Kirikkaleli et al. 2020; Nathaniel et al. 2020). Many political events have erupted over the needs for more energy, like the Persian Gulf War as well as continual conflicts in the Middle East (Hu et al. 2019). These reasons have led to greater research attention focusing on energy production and EPU in the energy and economic markets.

Considerable uncertainties that exist in policy can significantly impact the energy consumption behaviors of distributed energy systems and make their promotion more challenging. Many studies in the literature have investigated different resources from various economic systems, such as energy (Xia et al. 2017; Kan et al. 2019), land (Weinzettel et al. 2013; Wu et al. 2018), water (Chen et al. 2018b), materials (Plank et al. 2018), pollutant emissions like methane (Wang et al. 2019; Ma et al. 2018), mercury (Chen et al. 2019; Li et al. 2017), $\mathrm{PM}_{2.5}$ (Meng et al. 2016; Guan et al. 2014), as well as carbon emissions (Guan et al. 2018; Meng et al. 2018). Hamilton (1983) was the pioneer in EPU and energy consumption research, arguing that the two variables should be regarded as tightly connected among energy price shocks that result in energy demand and supply changes, as well as the negative influence they have on macroeconomic developments. Adedoyin and Zakari (2020) present a vital role of EPU in the UK's energy consumption and $\mathrm{CO}_{2}$ emission relationship and showed that EPU has opposite effects in short-run (positive) and long-run (negative) environment protection. Among these research studies, no special attention has yet been placed on the disaggregate energy and uncertainty factors of economic policies. Energy consumption is regarded as a corollary of economic activity, especially for a country like China that heavily relies on energy. However, the question between energy consumption and EPU still remains.

The related literature on EPU generally looks at political or economic activities. Bloom (2009) presents the political and economic factors that can bring about EPU. Baker et al. (2016) point out that uncertainty factors can affect the intensity of economic recessions and subsequent recoveries, by

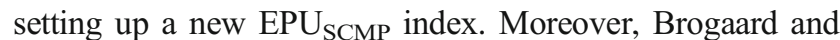
Detzel (2015) propose an asset-pricing model with EPU as a risk element. There are also some studies on the oil market and EPU, such as Bekiros et al. (2015) who offer that when predicting oil price changes, EPU cannot be ignored, while Aloui et al. (2016) present more proof about higher 
uncertainty bringing about a significant rise in crude oil returns over given periods. Kang et al. (2017a) further point out the effect is negative between $\mathrm{EPU}_{\mathrm{SCMP}}$ and oil returns, and they also conduct research about how EPU $\mathrm{SCMP}_{\mathrm{SC}}$ responds variously to the US national and foreign oil production changes (Kang et al. 2017b). Furthermore, Uddin et al. (2018) show strong heterogeneity among crude oil markets and geopolitical uncertainty components during different time periods. Though there are some studies about EPU $\mathrm{SCMP}_{\text {and the crude }}$ oil market, there is scant literature on the energy market and EPU $U_{\text {SCMP }}$, which is one of this paper's motivations.

The literature above always places attention on how EPU influences the energy market (mainly crude oil prices) in the time domain, but the frequency perspective is ignored (Yang 2019; Hailemariam et al. 2019; Adedoyin and Zakari 2020). Another issue of structural breaks is also mainly neglected in past research. Structural breaks, which most possibly exist in various time series periods, may lead to missing information of such structural breaks in the dataset (Lee 2013; Hu et al. 2019; Chen et al. 2014). Moreover, traditional analyses are comprised of the time or frequency domain. Therefore, market participants cannot respond to transient shocks, and energy producers are unable to change their production until significant shocks emerge in the energy market over a long period. Indeed, short- and long-term changes always differ among energy economic research (Wang and Wu 2013).

Identifying the dynamic co-movements and causalities among disparate energy productions and $\mathrm{EPU}_{\mathrm{SCMP}}$ can have important meanings in both the time and frequency domains. We also consider the cointegration nexus with structural breaks among the variables, and fresh empirical evidence can lead to more targeted energy policy implications and contribute to forecasting energy decisions under high uncertainty of energy market participants.

\section{Methodology}

Before employing wavelet analysis of the energy variables and $\mathrm{EPU}_{\mathrm{SCMP}}$, first of all, we adopt the unit root test with structural changes of Perron and Yabu (2009), the Lagrange Multiplier (LM) unit root test proposed by Lee and Strazicich 2003, 2004), and the Generalized Least Squares (GLS) based univariate unit root test with multiple structural breaks presented by Carrión-i-Silvestre et al. (2009). After getting stationary evidence, we next adopt the Gregory and Hansen (1996) analysis to find the cointegration relationship of dispa-

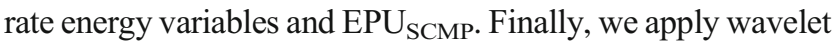
co-movement analysis presented by Aguiar-Conraria and Soares (2011) as well as Aguiar-Conraria et al. (2012) to show high-and low-frequency co-movements of the sample periods.

\section{Unit root and cointegration test with structural breaks}

We examine mean-reverting behaviors of the series and take unit root tests presented by Perron and Yabu (2009) to look into whether there exists any structural change in the deterministic factors of energy production and EPU $\mathrm{SCMP}_{\mathrm{SC}}$. We here employ the third model test of Perron and Yabu (2009) to investigate the long-run trends, ${ }^{5}$ later employ the LM unit root test with two structural breaks provided by Lee and Strazicich 2003, 2004), taking the data generating process (DGP) proposed by Perron (1989) into account, and assert eight is the maximum lag for serial correlation in accordance with the specific measure presented by Ng and Perron (1995). ${ }^{6}$ To find more evidence of mean-reverting behaviors, we also briefly enucleate the advantages of the time series unit root test based on GLS, proposed by Carrión-i-Silvestre et al. (2009). Compared with other traditional tests, two primary merits are presented of the GLS-based test: it supports potential multiple breaks via both alternative and null hypotheses of stable trends; and endogenous multiple breakpoints are considered. Applying the GLS-based unit root test, we attain multiple structural breaks, which will result in stronger stationary evidence of the variables. ${ }^{7}$

After investigating the unit root tests with structural breaks, we next present the cointegrated model of energy production and EPU $_{\mathrm{SCMP}}$, testing the interactions among the variables relying on the Chinese sample. Then, we examine the cointegration relationships of the variables.

$Y_{\mathrm{it}}=a_{0} X_{i t}+\nu_{i t}$,

where $Y$ implies energy production at time $t$ and type $i$; we define OIL as type 1, COAL as type 2, GAS as type 3, ELEC as type 4 and RENEW as type $5 ; X$ implies EPU $\mathrm{SCMP}_{\mathrm{SP}}$; and $\nu$ indicates the white noise error term. By applying the cointegrated examinations with structural breaks, we will attain stronger evidence and more precise findings (Lee and Chang 2008).

We thus adopt cointegration examination with structural breaks by the time series sample, which is provided by Gregory and Hansen (1996) to find the relationship among disparate energy productions and EPU $\mathrm{SCMP}_{\text {. Gregory and }}$ Hansen (1996) assume no cointegration as the null hypothesis, and $A D F, Z_{\alpha}$, and $Z_{t}$ tests are adopted to survey the level or regime shifts of disparate energy productions and $\mathrm{EPU}_{\mathrm{SCMP}}$. We utilize the three shift models presented by Gregory and Hansen (1996): level shift (C), level shift with trend (C/T), as well as regime shift $(\mathrm{C} / \mathrm{S})$. The cointegration tests are utilized for each probable regime shift $\tau \in T$, showing the smallest

\footnotetext{
$\overline{5}$ Please see the details in Perron and Yabu (2009).

${ }^{6}$ Please see the details in Lee and Strazicich (2003, 2004).

${ }^{7}$ Please see the details in Carrión-i-Silvestre et al. (2009).
} 
value by the above analyses among entire potential structural breakpoints. $^{8}$

\section{Wavelet analysis}

The continuous wavelet transform presented by AguiarConraria and Soares (2011) and Aguiar-Conraria et al. (2012) is utilized in our empirical tests. ${ }^{9}$ The primary merit of wavelet analysis is making it possible to present the signal containing both in time domain as well as frequency one. When comparing with Fourier analysis, which is not only completely lost in the time information, but also makes it difficult to discriminate the temporary nexus or recognize breakpoints (Aguiar-Conraria and Soares 2011). Wavelet analysis, as an alternative, which is different from the Fourier transform functions, decreases towards zero. This is required that the wavelet transform to own zero mean and suppose a decaying characteristic, indicating the transform fluctuates increase and drop the t-axis when it approaches zero. According to Aguiar-Conraria et al. (2012), the wavelet analysis just presents a small wave losing strength when it moves away from the center. This characteristic proposes us a valid localization in both time and frequency sights.

Using a given time series $\chi(t)$, the continuous wavelet transform (CWT) for a wavelet function $\xi$ presented as $W_{\chi}(\alpha, \beta)$ is a function of two variables:

$W_{\chi}(\alpha, \beta)=\int_{-\infty}^{\infty} \chi(t) \frac{1}{\sqrt{\alpha}} \xi^{*} \frac{(t-\beta)}{\alpha} d t$

Here, $\alpha$ and $\beta$ indicate the parameters denoting scale as well as location one; the former implies the wavelet length, while the latter presents the wavelet center; and $*$ indicates the complex conjugate. The scale shows an opposite nexus to frequency, and a lower/higher scale implies a less/more constringent wavelet, which is capable of finding higher/lower frequency time series sample. The composition of wavelet analysis $W_{\chi}$ contains $R\left(W_{\chi}\right)$ as a real section, $I\left(W_{\chi}\right)$ as an imaginary section, as well as amplitude, $\left|W_{\chi}\right|$, phase, and $\tan ^{-1}\left[\frac{I\left(W_{\chi}\right)}{R\left(W_{\chi}\right)}\right]$, ranging from $-\beta$ to $\beta$, which is parameterized in radians. In accordance with the continuous wavelet transform, the sample's wavelet power spectrum is divided under wavelet co-movement (Vacha and Barunik 2012).

Similar to Aguiar-Conraria and Soares (2011), we present the wavelet transform between the series as follows. The Monte-Carlo simulations are designed in accordance with Schreiber and Schmitz (1996) by adopting the amplitudeadjusted Fourier transform. The wavelet co-movement analysis presents the proportion of the cross-spectrum for disparate

\footnotetext{
8 The details are in Gregory and Hansen (1996).

9 The main section of wavelet analysis is described in this part, which greatly based on the work of Aguiar-Conraria and Soares (2011).
}

energy productions of the spectrum series with time frequencies.

$$
\begin{gathered}
R_{n}(\alpha)=\frac{\mid S\left(\alpha^{-1} W_{n}^{x y}(\alpha) \mid\right.}{S\left(\alpha^{-1}\left|W_{n}^{x}\right|\right)^{\frac{1}{2}} S\left(\alpha^{-1}\left|W_{n}^{y}\right|\right)^{\frac{1}{2}}}, \\
W_{n}^{x y}=W_{n}^{x} W_{n}^{y^{*}} .
\end{gathered}
$$

Here, $S$ represents the smoothing operator both with time and scale. As the theoretical distribution for the wavelet analysis has been unknown (Vacha and Barunik 2012), we next examine the statistical significance by adopting Monte Carlo methods of wavelet analysis, according to Schreiber and Schmitz (1996) and Aguiar-Conraria and Soares (2011). The phase-difference $\eta_{x, y}$ between series $x(t)$ and $y(t)$ can be presented as follows:

$$
\begin{gathered}
\eta_{x, y}=\tan ^{-1}\left(\frac{I\left(W_{n}^{x y}\right)}{R\left(W_{n}^{x y}\right)}\right), \\
\eta_{x, y} \in[-\pi, \pi] .
\end{gathered}
$$

Here, when the time series moves in phase (positive causality) and $\eta_{x, y} \in(\mathbf{0}, \pi / 2)$, it means series $y(t)$ leads to $x(t)$; while for $\eta_{x, y} \in(-\pi / 2,0), x(t)$ plays the leader role, whereas when the phase-difference is $\pi$ or $-\pi$, we define it as an antiphase nexus which is out of phase (negative causality). For a phase-difference of $\eta_{x, y} \in(\pi / 2, \pi)$, series $x(t)$ leads to $y(t)$. Furthermore, when $\eta_{x, y} \in(-\pi,-\pi / 2), y(t)$ occupies the leading position.

We therefore adopt wavelets to examine the co-movement between energy production and $\mathrm{EPU}_{\mathrm{SCMP}}$-i.e., COAL vs. EPU $_{\text {SCMP }}$, OIL vs. EPU SCMP $_{\text {, GAS vs. EPU }}$ SCMP, ELEC vs.

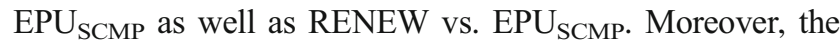
wavelet power spectrum indicates a time series variance evolution at various frequencies, while wavelet co-movement means a localized correlation coefficient in both time and frequency domains. Information on the delay between the sample's oscillation, which can be investigated through the phase-difference. $^{10}$

\section{Data description and empirical results}

\section{Data description}

This section presents the dataset so that we can discuss the corresponding summary statistics. The dataset is from January 1995 to October 2019. We measure energy production by applying the variables COAL, OIL, GAS, ELEC, and

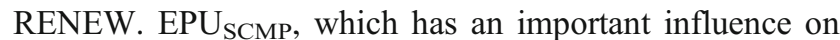

\footnotetext{
${ }^{10}$ The detailed exposition of the wavelet analysis is in Aguiar-Conraria and Soares (2011).
} 
economic and financial activities, has a close relationship with energy consumption and energy production and helps promote new energy technology development to stimulate energy efficiency (Li and Lin 2016; Antonakakis et al. 2014; Bekiros et al. 2015). We utilize the EPU $\mathrm{SCMP}_{\text {index in China provided }}$ by Baker et al. (2016), which relies on screening relevant key words in newspapers; here, a higher EPU $\mathrm{SCMP}_{\mathrm{SC}}$ represents higher uncertainty. ${ }^{11}$ More details of the EPU $\mathrm{SCMP}_{\text {index can }}$ be seen in Baker et al. (2016).

Figure 1 depicts how disparate energy productions and EPU $_{\text {SCMP }}$ fluctuate during the time period. The pattern of the COAL-EPU $\mathrm{SCMP}_{\mathrm{P}}$ figure witnesses two significant intersection points at the beginning of the 2000s and the end of the 2010s. From 2002-2019, the two lines move in opposite direction. The COAL-EPU $\mathrm{SCMP}_{\mathrm{S}}$ frequencies vary in the time domain; the main reasons are that China joined World Trade Organization (WTO) in 2001 and the world financial crisis in 2008, which can bring about the remarkable decrease of the COALEPU $_{\text {SCMP }}$ figure. Hence, we see the OIL-EPU SCMP $_{\text {plot, which }}$ always fluctuates until the 2010s, may be urged by the sharp shale energy boom in the global energy market. Next, the GASEPU $_{\text {SCMP }}$, ELEC-EPU SCMP $_{\text {and RENEW-EPU }}$ SCMP figures manifest a similar plot as well as the co-movements at the end of 1990s, the early 2000s, and the end of 2010s. ${ }^{12}$

Table 1 also provides the descriptive statistics for COAL,

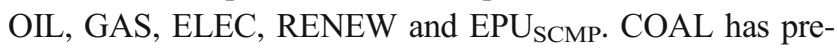
dominance among the variables over all test statistics, indicating that coal will help maintain dependable and safe disparate energy consumptions in China during the next 20 years (Qin

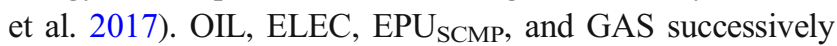
follow COAL, which mean the gas industry in China needs to make more efforts at natural gas development. The result of RENEW shows that the renewable energy is becoming more and more important in China's energy market, but need more attentions and policies to support the renewable development. Furthermore, the statistics of standard deviation always swing in the time domain, meaning structural changes most likely exist in the period.

\section{Empirical findings}

\section{Evidence from unit root tests with structural breaks}

To find whether or not there are any external shocks in the persistent components of our variables, we employ the Perron and Yabu (2009) unit root test. Table 2 presents the test statistic Exp- $\mathrm{W}_{\mathrm{RQF}}$ as well as structural locations of energy production and $\mathrm{EPU}_{\mathrm{SCMP}}$. It is significant to account for possible

\footnotetext{
11 The EPU $\mathrm{SCMP}_{\mathrm{S}}$ index is available at www. policyuncertainty. com.

12 In accordance with the World Trade Statistical Review 2016 published by WTO, in the period of 2014-2015, the dramatic decrease in world trade was attributed to potential reasons such as a severe recession in Brazil, the economic slowdown in China, exchange rate volatility, and so on.
}

breaks when examining the mean-reverting properties of our variables, and more stationarity evidence is needed for a search. We hence adopt the Lee and Strazicich 2003, 2004) tests with two structural breaks.

Table 3 further provides Model AA, Model CC as well as its structural locations findings, showing that energy production and $\mathrm{EPU}_{\mathrm{SCMP}}$ both accept the alternative hypothesis of stationarity. For Model AA and Model CC, we prefer the latter as a more convincing and accurate measure (Sen 2003) than the former. Model CC always represents better than Model AA while applying the Monte Carlo simulations following structural breaks. Since the external shocks should have more than one or two break locations, multiple structural breaks need to be considered in our research. Next, we utilize the Carrión-iSilvestre et al. 2009) GLS-based unit root test through looking at two and five structural breaks. Finding stronger evidence of mean-reverting property for time series sample with structural breaks is our target. We utilize the $\mathrm{I}(0)$ and $\mathrm{I}(1)$ processes of the variables to get more evidence for the stationary characteristics. Tables 4 and 5 present the GLS-based analyses with two and five breaks of Models AA and Model CC, respectively, and more mean-reverting behaviors under the first difference process. ${ }^{13}$ The breakpoints focus on 2008 (global financial crisis) as well as 2015-2016 (dramatic fall in global trade), causing China's sharp economic slowdown that also filters into the energy market (Dong et al. 2019).

\section{Evidence from cointegration test with structural breaks}

Based on the unit root tests of stationarity property, we next investigate energy production and $\mathrm{EPU}_{\mathrm{SCMP}}$ for a cointegration relationship. We employ the Gregory and Hansen (1996) time series cointegration test with structural breaks. Table 6 denotes the findings of the $A D F^{*}, Z_{t}^{*}$, and $Z_{\alpha}^{*}$ tests of Gregory and Hansen (1996), when the cointegration variables consider one structural break. All three models can almost verify with the alternative hypothesis, i.e., a cointegrated nexus with structural breaks. Taking Model C (the level shift model) into account, we attain powerful proof of cointegrated relationship with structural breaks adopting the three tests, indicating nearly all the results reject the no cointegration hypothesis. The $\mathrm{C} / \mathrm{T}$ (level shift with trend mod$\mathrm{el}$ ) and $\mathrm{C} / \mathrm{S}$ (regime model) results present strong proof for the cointegrated findings with structural breaks, meaning the cointegration relationship of energy production and EPU $_{\text {SCMP }}$ can be supported by the examinations. Taking structural breaks into account, all the models denote the break locations are during the period from March 2006 to September 2009, which match more of the shale gas revolution and the global financial crisis.

\footnotetext{
${ }^{13}$ The same break locations for both the two and five structural break analyses are in the tables with bold text.
} 

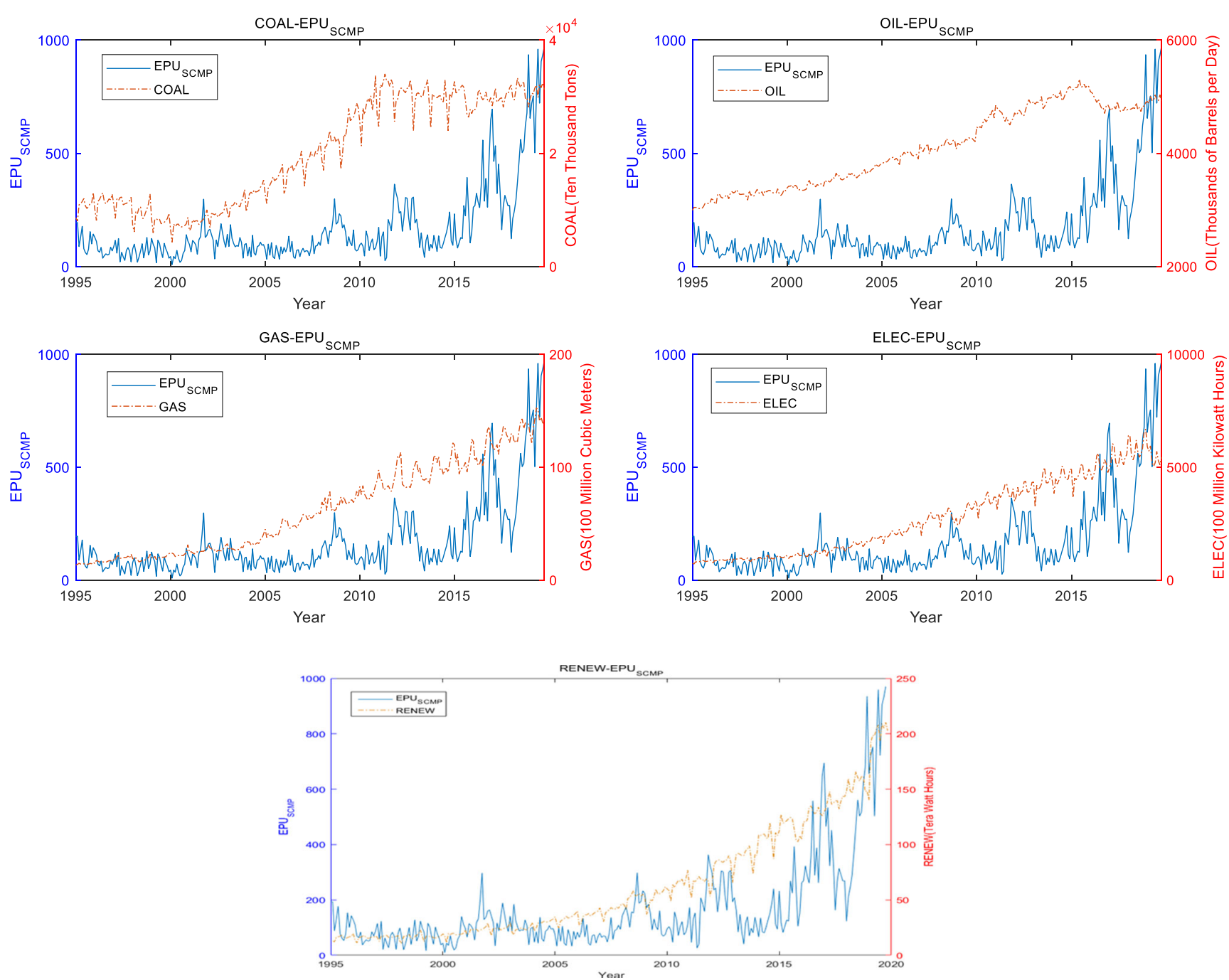

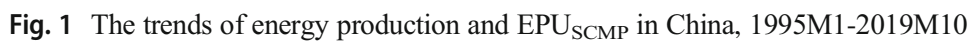

\section{Evidence from the wavelet co-movement and phase difference}

Although the former test presents cointegration relationship between energy production and EPU $\mathrm{SCMP}_{\mathrm{S}}$, we are a bit dissatisfied with only one piece of cointegration evidence to representative the dynamic co-movement in the variables' interactive proceeding. Thus, we adopt wavelet analysis in both time

Table 1 Descriptive statistics

\begin{tabular}{llllll}
\hline Variables & Mean & Std. dev. & Median & Max & Min \\
\hline COAL & 19846.487 & 9392.688 & 18906.860 & 34020.080 & 4298.170 \\
OIL & 4106.666 & 682.854 & 4067.240 & 5310.683 & 2995.000 \\
GAS & 62.960 & 40.293 & 57.470 & 152.500 & 13.320 \\
ELEC & 2811.675 & 1674.692 & 2528.680 & 6682.400 & 712.700 \\
RENEW & 736.663 & 581.667 & 490.196 & 2022.631 & 189.606 \\
EPU & 169.496 & 173.132 & 107.965 & 9.067 & 970.830 \\
\hline
\end{tabular}

and frequency domains, to examine the dynamic interaction

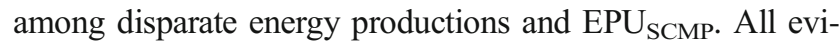
dence about structural breaks can be presented through a phase-difference technology in our sample (Aguiar-Conraria and Soares 2011; Chang and Lee 2015).

Figures 2, 3, 4, 5, to 6 present the wavelet co-movements and phase differences of the sample between COAL vs.

Table 2 PY unit root tests with structural break

\begin{tabular}{llllll}
\hline & Exp-W-RQF & Break date & $\operatorname{cv}(1 \%)$ & $\mathrm{cv}(5 \%)$ & $\mathrm{cv}(10 \%)$ \\
\hline COAL & 6.156 & 200904 & 4.470 & 3.120 & 2.480 \\
OIL & 3.356 & 201004 & 4.470 & 3.120 & 2.480 \\
GAS & 11.130 & 200409 & 4.470 & 3.120 & 2.480 \\
ELEC & 4.861 & 200201 & 4.470 & 3.120 & 2.480 \\
RENEW & 66.739 & 201002 & 4.470 & 3.120 & 2.480 \\
EPU & 2.182 & 201501 & 4.470 & 3.120 & 2.480 \\
\hline
\end{tabular}

Notes: Trimmer parameter is equivalent to 0.15 . The critical values can be checked out from Table 2 in the work of Perron and Yabu (2009) 
Table 3 Univariate LM unit root test with two structural breaks

\begin{tabular}{|c|c|c|c|c|c|c|c|c|c|c|c|c|}
\hline \multirow[t]{2}{*}{ Variables } & \multicolumn{5}{|c|}{ Model AA } & \multicolumn{7}{|c|}{ Model CC } \\
\hline & $\mathrm{TB}_{1}$ & $\mathrm{~TB}_{2}$ & $\mathrm{~S}_{\mathrm{t}-1}$ & $\mathrm{~B}_{\mathrm{t} 1}$ & $\mathrm{~B}_{\mathrm{t} 2}$ & $\mathrm{~TB}_{1}$ & $\mathrm{~TB}_{2}$ & $\mathrm{~S}_{\mathrm{t}-1}$ & $\mathrm{~B}_{\mathrm{t} 1}$ & $\mathrm{~B}_{\mathrm{t} 2}$ & $\mathrm{D}_{\mathrm{t} 1}$ & $\mathrm{D}_{\mathrm{t} 2}$ \\
\hline COAL & 200702 & 200802 & -0.085 & 0.046 & $0.076^{*}$ & 200002 & 201005 & $-0.591^{*}$ & $0.128^{*}$ & 0.001 & $-0.099^{*}$ & $0.037^{*}$ \\
\hline OIL & 200612 & 201506 & -0.060 & $0.098^{*}$ & $-0.034^{*}$ & 200911 & 201605 & $-0.845^{*}$ & $-0.052^{*}$ & $0.040^{*}$ & $0.034^{*}$ & $-0.047^{*}$ \\
\hline GAS & 200804 & 201511 & -0.107 & $0.082^{*}$ & $0.093^{*}$ & 200304 & 201303 & $-0.966^{*}$ & 0.004 & $-0.064^{*}$ & $-0.005^{*}$ & $0.008^{*}$ \\
\hline ELEC & 199901 & 201002 & -0.158 & $-0.050^{*}$ & $0.080^{*}$ & 200111 & 201610 & $-0.810^{*}$ & 0.040 & $-0.061^{*}$ & $-0.024^{*}$ & $0.063^{*}$ \\
\hline RENEW & 201410 & 201412 & -1.858 & $2.869^{* * * *}$ & $1.392^{* *}$ & 200702 & 201407 & $-7.423^{\text {**** }}$ & $1.364^{* *}$ & $3.140^{* * * *}$ & -1.152 & -3.613 \\
\hline EPU & 201611 & 201704 & -0.099 & $0.233^{*}$ & 0.004 & 201603 & 201704 & $-0.407^{*}$ & -0.060 & $0.136^{*}$ & $0.118^{*}$ & $-0.115^{*}$ \\
\hline
\end{tabular}

The entries in bold are structural breaks with high frequent appearance

Notes: $B_{t 1}$ refers to the coefficient on the first break in the intercept; $B_{t 2}$ refers to the coefficient on the second break in the intercept; $D_{t 1}$ refers to the coefficient on the first break in the slope; and $\mathrm{D}_{\mathrm{t} 2}$ denotes the coefficient on the second break in the slope. ${ }^{*}$ indicates rejecting the null hypothesis of unit root with statistical significance at the $5 \%$ level, respectively

EPU $_{\mathrm{SCMP}}$, OIL vs. EPU $\mathrm{SCMP}_{\text {, GAS vs. EPU }}$ SCMP, ELEC vs. $\mathrm{EPU}_{\mathrm{SCMP}}$, as well as RENEW vs. EPU $\mathrm{SCMP}_{\mathrm{S}}$, respectively. The cone effect is presented as a black line, which is similar with "region," presenting the contour is significant at the 5\% level. The left graphs in each figure mean the wavelet co-movement findings, while the right graphs show the phase difference findings. In the wavelet co-movement analysis graphs, the vertical axis means the frequency converted into time units (month), while the horizontal axis indicates the time series diversifies slightly considering data availability diversifications of every issue. Co-movement ranges from red, implying low co-movement, to blue, meaning high co-movement. For instance, a blue area at the top (bottom) of the figures signifies strong co-movement at high (low) frequencies; however, a blue area at the right-hand (left-hand) side presents powerful co-movement at the end (start) of the time series. Furthermore, the color code ranges from red (low power/ co-movement) to blue (high power/ co-movement) for the wavelet power spectrum. For phase difference graphs on the right-hand side for presenting causality about the variables, the vertical axis implies the phase difference between the variables, when the horizontal axis presents time. We select the frequency band of 3-8 years to perform wavelet analysis, considering two reasons: external shocks always span 3-8 years of the energy production (Chang and Lee 2015), and business cycles usually take 3-8 years (Bergman et al. 1998).

Table 4 CKP GLS-based unit root test with two breaks (Model AA and Model CC)

\begin{tabular}{|c|c|c|c|c|c|c|c|c|c|c|}
\hline \multirow[t]{2}{*}{ Variables } & \multicolumn{5}{|c|}{ Model AA } & \multicolumn{5}{|c|}{ Model CC } \\
\hline & $P_{T}^{G L S}$ & $M P_{T}^{G L S}$ & $A D F^{G L S}$ & $\mathrm{~TB}_{1}$ & $\mathrm{~TB}_{2}$ & $P_{T}^{G L S}$ & $M P_{T}^{G L S}$ & $A D F^{G L S}$ & $\mathrm{~TB}_{1}$ & $\mathrm{~TB}_{2}$ \\
\hline \multicolumn{11}{|l|}{ Levels } \\
\hline COAL & $16.918^{*}$ & $16.639^{*}$ & -2.680 & 200702 & 200909 & $13.878^{*}$ & $12.657^{*}$ & -3.082 & 199812 & 200909 \\
\hline OIL & $23.159^{*}$ & $18.963^{*}$ & -2.368 & 200706 & 200912 & $15.273^{*}$ & $14.906^{*}$ & -2.695 & 200512 & 200912 \\
\hline GAS & $18.096^{*}$ & $16.452^{*}$ & -3.254 & 199806 & 200012 & $31.382^{*}$ & $28.887^{*}$ & -2.205 & 200012 & 201203 \\
\hline ELEC & $36.637^{*}$ & $33.513^{*}$ & -1.829 & 201302 & 201703 & $17.246^{*}$ & $16.053^{*}$ & -2.654 & 200708 & 201308 \\
\hline RENEW & $13.328^{*}$ & $12.618^{*}$ & -2.593 & 201111 & 201512 & $8.173^{*}$ & $7.870^{*}$ & -3.236 & 200901 & 201310 \\
\hline $\mathrm{EPU}_{\mathrm{SCMP}}$ & $7.109^{*}$ & $6.880^{*}$ & -3.494 & 200007 & 201511 & $10.482^{*}$ & $9.453^{*}$ & -2.955 & 200809 & 201511 \\
\hline \multicolumn{11}{|c|}{ Firstdifference } \\
\hline COAL & 1.920 & 1.291 & $-16.358^{*}$ & 201002 & 201210 & 1.331 & 1.282 & $-14.596^{*}$ & 200512 & 201011 \\
\hline OIL & 1.963 & 1.484 & $-19.090^{*}$ & 200706 & 201010 & 1.649 & 1.583 & $-12.859^{*}$ & 199902 & 200706 \\
\hline GAS & $2.294^{*}$ & $1.758^{*}$ & $-9.367^{*}$ & 201112 & 201503 & $1.835^{*}$ & $1.781^{*}$ & $-9.075^{*}$ & 200712 & 201112 \\
\hline ELEC & 1.748 & 1.263 & $-15.952^{*}$ & 201002 & 201301 & 2.161 & 2.082 & $-8.476^{*}$ & 200701 & 201301 \\
\hline RENEW & 1.714 & 1.307 & $-17.158^{*}$ & 201002 & 201210 & 1.559 & 1.498 & $-10.789^{*}$ & 201002 & 201210 \\
\hline $\mathrm{EPU}_{\mathrm{SCMP}}$ & 1.666 & 1.439 & $-21.712^{*}$ & 201211 & 201610 & 1.808 & 1.731 & $-10.433^{*}$ & 200109 & 201606 \\
\hline
\end{tabular}

The entries in bold are structural breaks with high frequent appearance

Notes: $\mathrm{TB}_{1}$ refers to the coefficient on the first break both in intercept and slope; $\mathrm{TB}_{2}$ indicates the coefficient on the second break both in intercept and slope. * implies rejecting the null hypothesis of unit root with statistical significance at the $5 \%$ level 


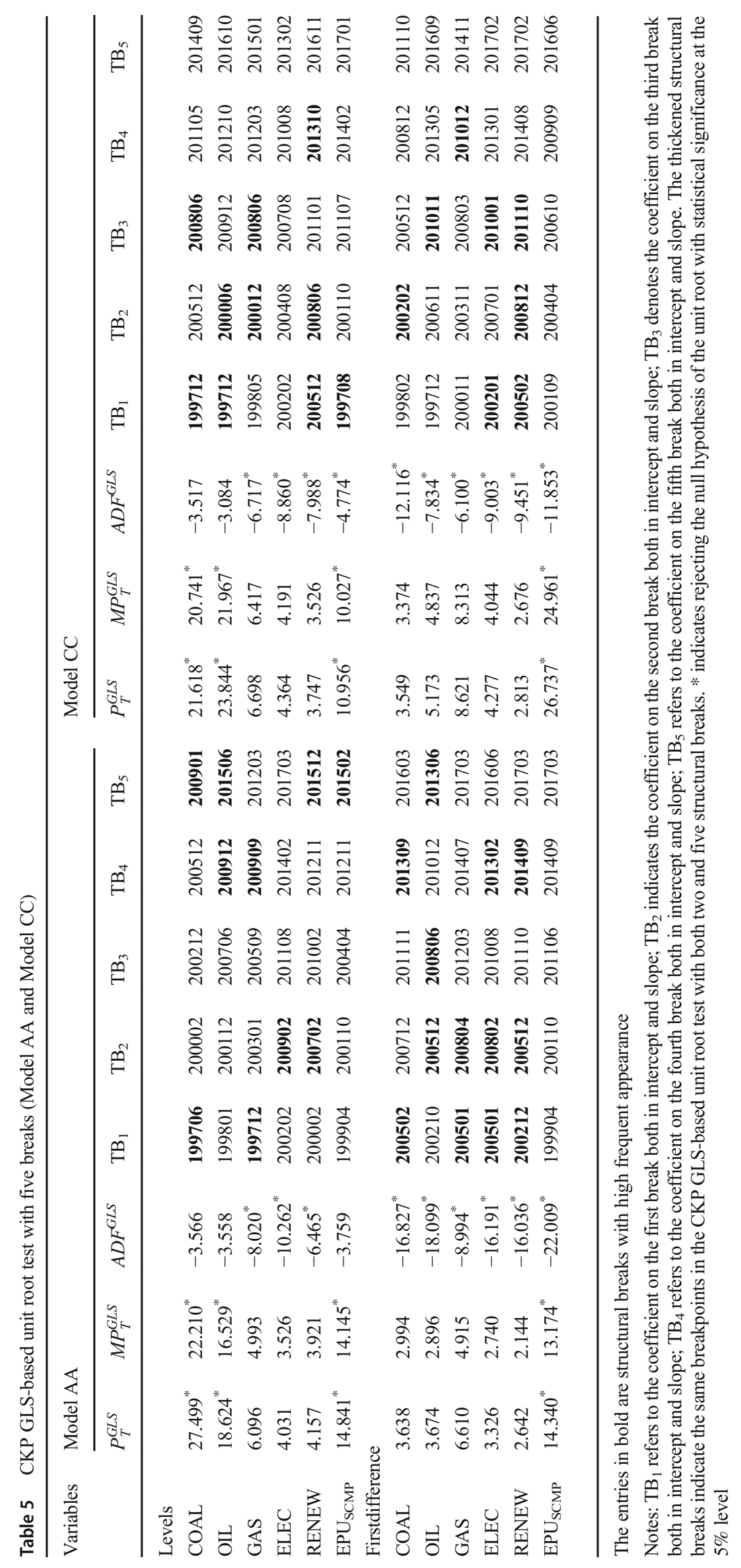


Table 6 GH time series cointegration test with structural break

\begin{tabular}{|c|c|c|c|c|c|c|c|c|c|c|}
\hline \multirow[t]{2}{*}{ Tests } & \multicolumn{2}{|l|}{ COAL } & \multicolumn{2}{|l|}{ OIL } & \multicolumn{2}{|l|}{ GAS } & \multicolumn{2}{|l|}{ ELEC } & \multicolumn{2}{|l|}{ RENEW } \\
\hline & T-statistic & Break date & T-statistic & Break date & T-statistic & Break date & T-statistic & Break date & T-statistic & Break date \\
\hline \multicolumn{11}{|l|}{$A D F^{*}$} \\
\hline$C$ & -3.843 & 200711 & -3.151 & 200807 & $-5.141^{*}$ & 200603 & -3.285 & 200810 & -4.462 & 201209 \\
\hline$C / T$ & -3.326 & 200809 & -3.671 & 200909 & -3.697 & 199910 & -4.917 & 199902 & $-8.063^{*}$ & 201211 \\
\hline$C / S$ & $-6.911^{*}$ & 200303 & $-6.302^{*}$ & 200909 & $-5.994^{*}$ & 200603 & $-6.291^{*}$ & 200810 & -4.581 & 201210 \\
\hline \multicolumn{11}{|l|}{$Z_{t}^{*}$} \\
\hline$C$ & $-5.653^{*}$ & 200712 & -3.026 & 200807 & $-5.041^{*}$ & 200603 & -4.781 & 200608 & $-6.354^{*}$ & 200907 \\
\hline$C / T$ & $-6.417^{*}$ & 200712 & $-5.436^{*}$ & 201003 & $-7.521^{*}$ & 199810 & $-9.576^{*}$ & 199902 & $-8.372^{*}$ & 201301 \\
\hline$C / S$ & $-8.140^{*}$ & 200206 & $-6.788^{*}$ & 201304 & $-5.902^{*}$ & 200603 & $-5.864^{*}$ & 200908 & $-6.625^{*}$ & 201210 \\
\hline \multicolumn{11}{|l|}{$Z_{\alpha}^{*}$} \\
\hline$C$ & $-57.412^{*}$ & 200712 & -15.600 & 200807 & -46.515 & 200603 & -42.273 & 200608 & $-68.512^{*}$ & 200907 \\
\hline$C / T$ & $-71.841^{*}$ & 200712 & -50.590 & 201003 & $-98.663^{*}$ & 199810 & $-143.265^{*}$ & 199811 & $-113.682^{*}$ & 201301 \\
\hline$C / S$ & $-96.456^{*}$ & 200206 & $-59.717^{*}$ & 201304 & -45.097 & 200603 & $-62.541^{*}$ & 200908 & $-73.642^{*}$ & 201209 \\
\hline
\end{tabular}

The entries in bold are structural breaks with high frequent appearance

Notes: $C, C / T$, and $C / S$ present the Gregory and Hansen (1996) three models; i.e., the level shift, the level shift with trend, and with the regime shift, respectively. Numbers in the parentheses denote the structural breaks tested by Gregory and Hansen (1996). ${ }^{*}$ refers to the no cointegration hypothesis is rejected at the $5 \%$ level

From the wavelet co-movement results, we see some interesting patterns. Significant dynamic co-movement exist between energy production and $\mathrm{EPU}_{\mathrm{SCMP}}$ in both time and frequency domains, which is diverse from conventional cointegration test that only has a single integration nexus. From Figs. 2, 3, 4, 5, to 6, we obtain a similar pattern. All areas implying high frequencies, particular fluctuations for periods of less than 1.5 years are red. This indicates the comovement level among disparate energy productions and $\mathrm{EPU}_{\mathrm{SCMP}}$ is strong at high frequencies; i.e., in the short run

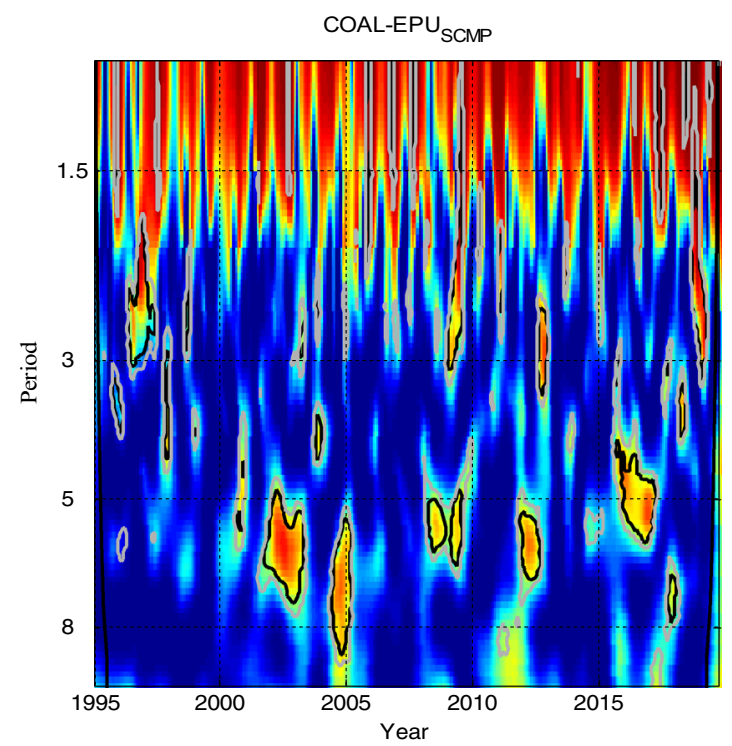

Fig. 2 COAL-EPU ${ }_{S C M P}$ wavelet co-movements and phase-differences. Notes: On the left: wavelet co-movement; on the right: a phase-differences. The cone effect is presented with a black line at the $5 \%$ significance for the total time series. The short-term results show that EPU $_{\text {SCMP }}$ is a vital component to be accounted for by shortterm energy investment in the energy market.

The co-movement between the special energy product and EPU $_{\text {SCMP }}$ is contrarily weaker at lower frequencies. Energy production and $\mathrm{EPU}_{\mathrm{SCMP}}$ just present a high co-movement level for the 5-8 years frequency bands. This reveals that EPU $_{\text {SCMP }}$ is gradually of less concern for energy market participants using a long-term view. Third, the wavelet comovement results also present a dynamic relation between

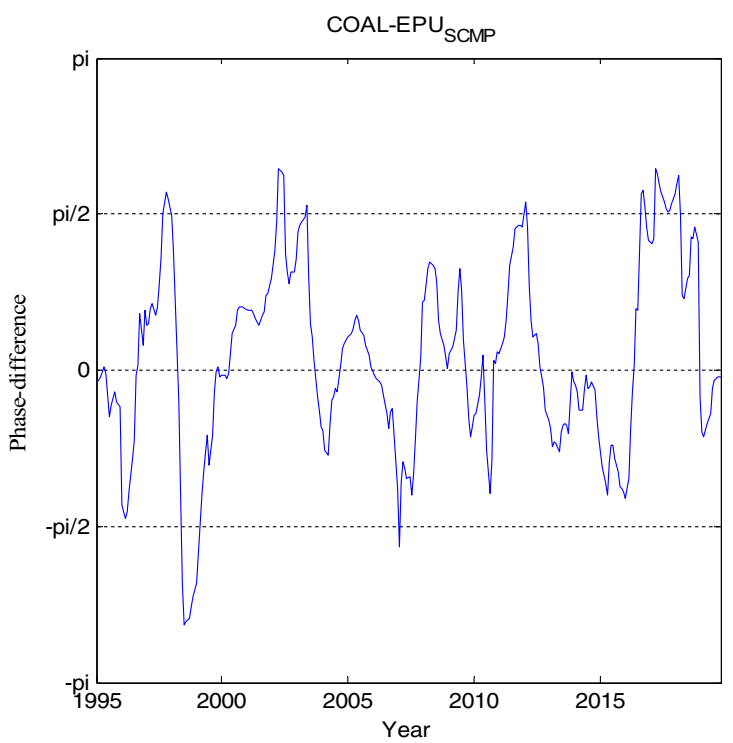

level. Co-movement ranges from blue (lower degree of dependence) to red (higher degree of dependence). The y-axis means frequencies; the $\mathrm{x}$ axis denotes the time period tests. On the right: phase-difference line 


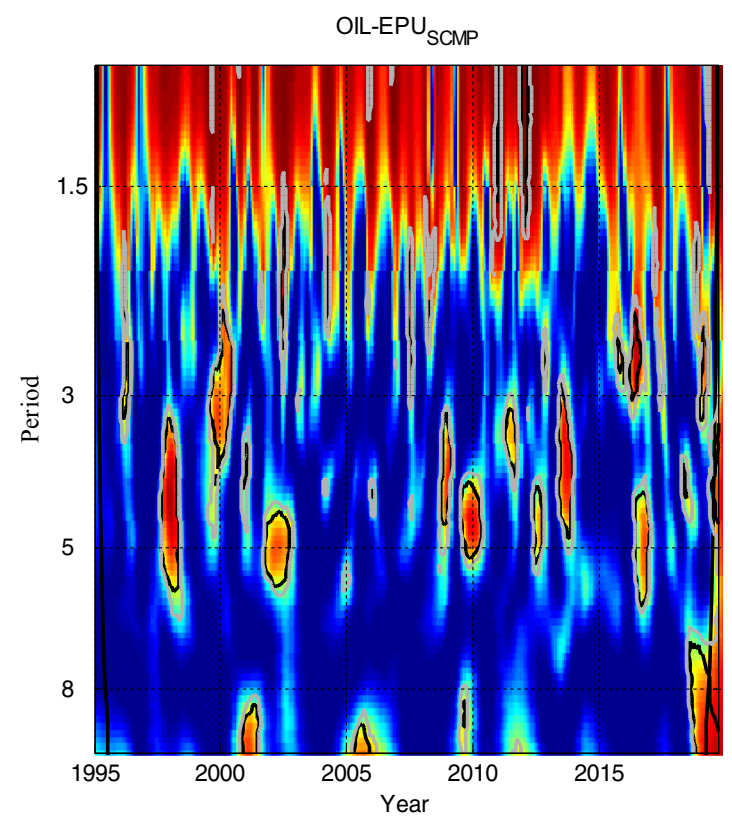

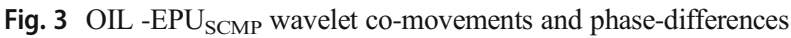

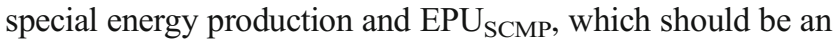
important factor in the decision-making progress of energy market participants. The structural breaks during the above time series mean a strong co-movement at low frequencies, which can offer a potential reappearance of a similar comovement near the forecasting future. Energy market participants should always pay close attention to $\mathrm{EPU}_{\mathrm{SCMP}}$ for excess return.

Since wavelet co-movement cannot distinguish whether the time series exhibit positive or negative co-movements, we adopt phase difference analysis to investigate the lead-

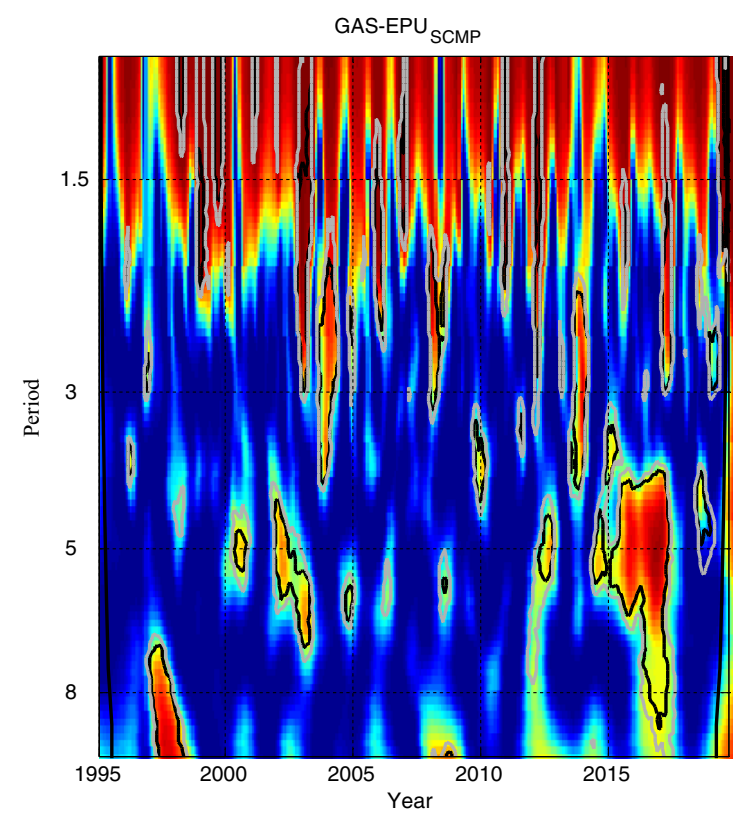

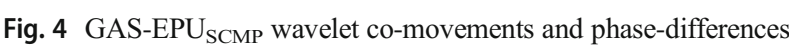

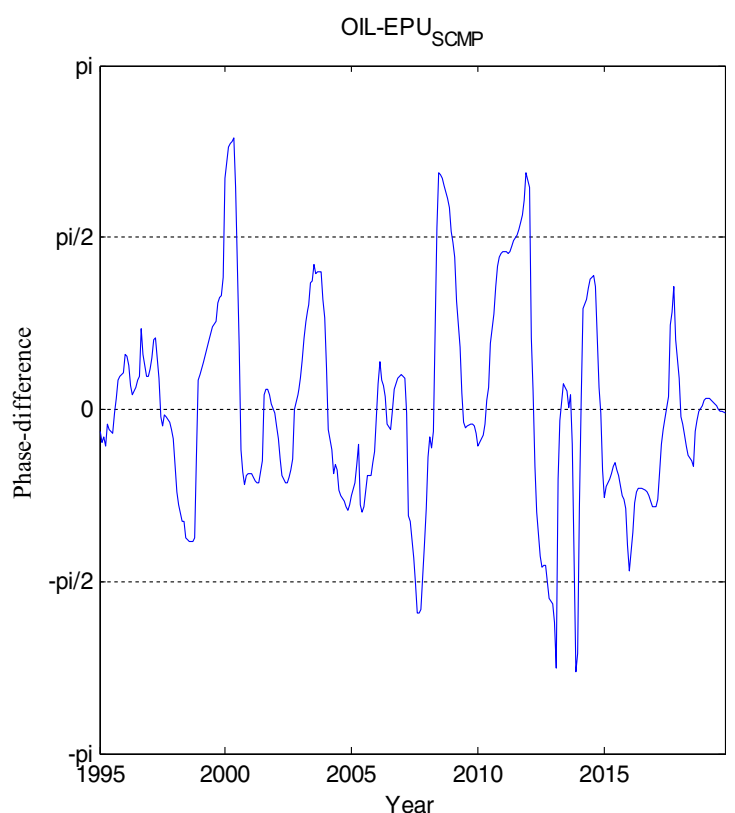

lag relationship as well as positive/negative causality among the disparate energy productions and EPU $\mathrm{SCMP}_{\mathrm{P}}$, subsequently. From Fig. 2, shown in the COAL-EPU $U_{\mathrm{SCMP}}$ plot, the phase difference is in-between $(0, \pi / 2)$ during various time domains. The explanation is in these time domains the variables are moving in phase; i.e., positive causality; and COAL leads $\mathrm{EPU}_{\mathrm{SCMP}}$, implying that the positive shocks of COAL on EPU $_{\text {SCMP }}$ take place in the time domain. In other words, a rise

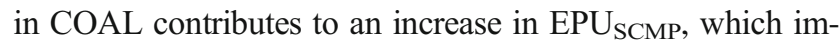
plies the increase of COAL will bring forth the authorities' reorientation of policy direction and then raise $\mathrm{EPU}_{\mathrm{SCMP}}$. On

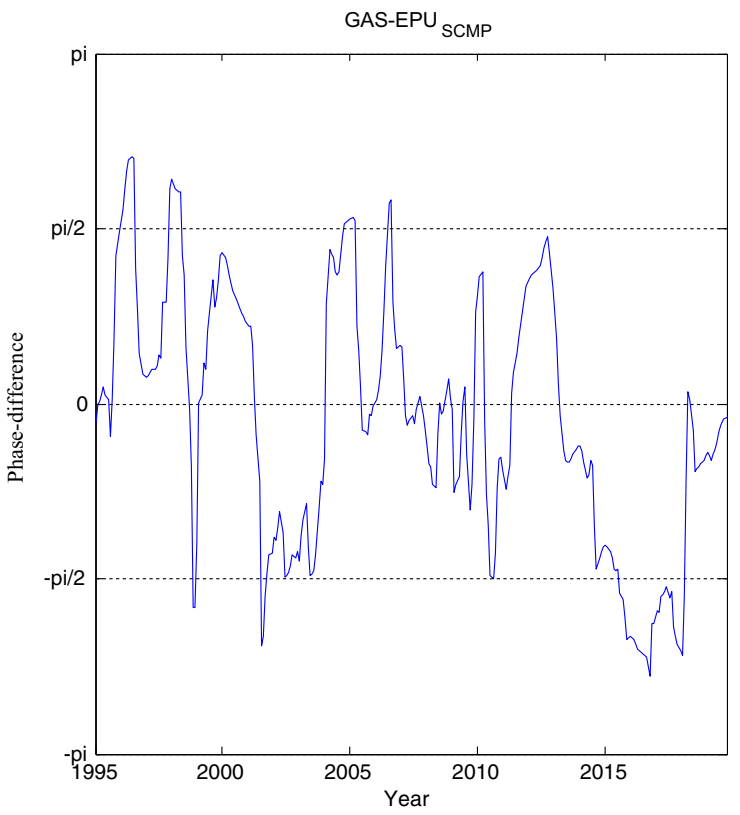




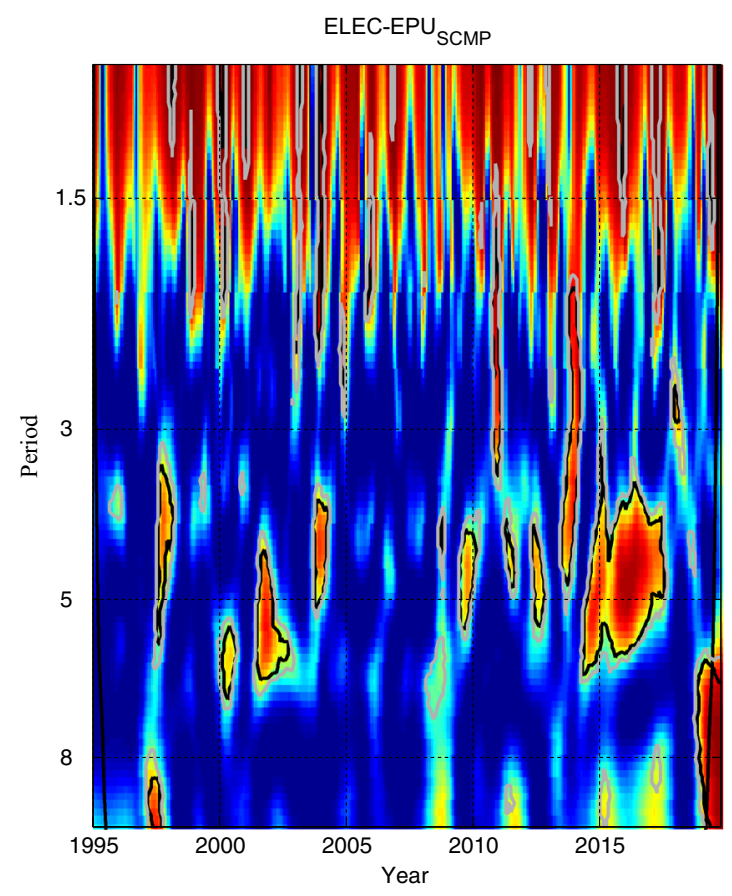

Fig. 5 ELEC-EPU $\mathrm{SCMP}_{\mathrm{S}}$ wavelet co-movements and phase-differences

the contrary, in the course of almost entire remaining time series, the phase difference locates in-between $(-\pi / 2,0)$, suggesting evidence that $\mathrm{EPU}_{\mathrm{SCMP}}$ leads COAL with a positive causality. It implies an increase in $\mathrm{EPU}_{\mathrm{SCMP}}$ serves to damage COAL. ${ }^{14}$

We next perform wavelet co-movement and phase difference to discuss the nexus between OIL and EPU $\mathrm{SCMP}_{\text {(Fig. 3). }}$ A positive causality exists in the short-term period, while the long-run period presents a negative nexus. The phase difference locates in-between $(0, \pi / 2)$, which includes the time periods of 1997-1998, early 2010s, as well as 2016-2018.

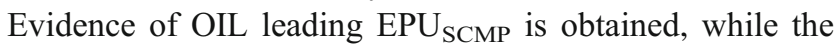
phase difference lies in-between $\left(-\pi /{ }_{2}, 0\right)$, means EPU $\mathrm{SCMP}_{\mathrm{S}}$ leads OIL, and a positive causality arises, which indicates that the positive shocks of EPU $U_{\mathrm{SCMP}}$ on OIL take place in the time domain.

Figure 4 offers evidence of wavelet co-movement and phase difference results for GAS and EPU $\mathrm{SCMP}_{\text {. Similar to }}$

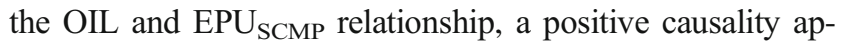
pears in the short term, while a negative nexus exists in the long run period. Moreover, in Figs. 5-6, we provide wavelet co-movement and phase difference analysis of ELEC, RENEW and EPU $\mathrm{SCMP}_{\text {, respectively. The short-term result }}$ is always significant, while the long-term is opposite. Overall, our results identify two important points: 1) a strong positive causality at the high frequency band, particularly with

\footnotetext{
${ }^{14}$ We also obtain that the phase difference can be marginally above $\pi / 2$ or below $-\pi / 2$ in very short series. Though the proof is comparatively weak, we assert that dynamic causality among disparate energy productions and $\mathrm{EPU}_{\mathrm{SCMP}}$ moves in phase.
}

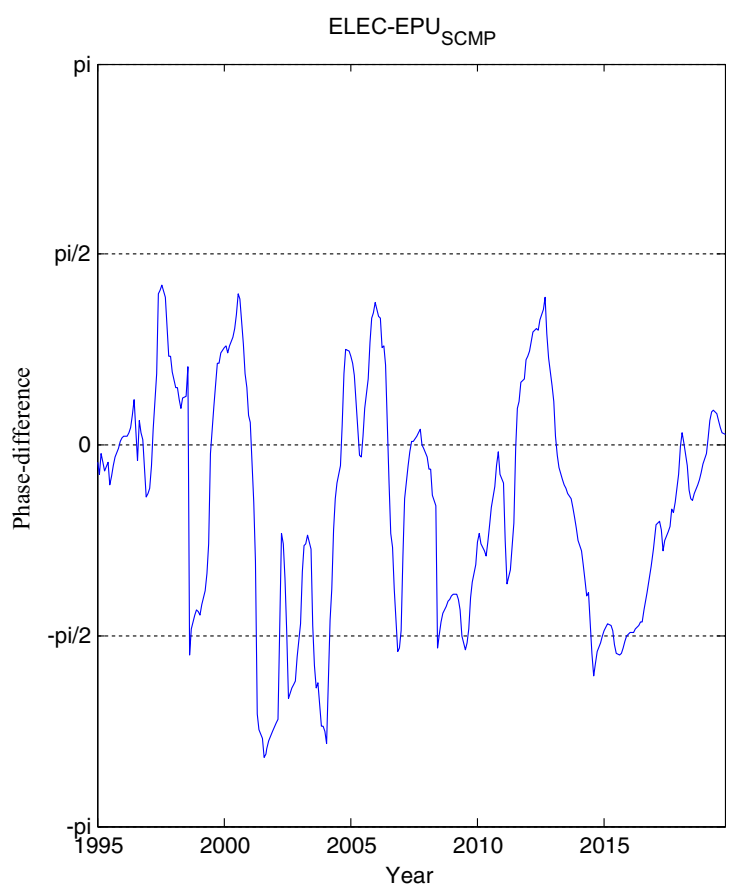

a change duration of less than one and a half years; and 2) at lower frequencies there is a relatively weaker causality. These results suggest that short-term energy investors need account for purchasing more assets.

The structural breaks always locate in the time periods of 1997-1999, 2000-2002, 2007-2011, and 2014-2016, which basically match the former unit root tests and cointegration tests with structural breaks. This interesting result may involve several widely known events. In 1997, the Asian financial crisis burst forth, which shocked China's economic and energy markets, bringing about much uncertainty to the country; in 2001, China joined WTO following many stages of development; in 2008, the global financial crisis sharply shook the world, and economic slumps continued for years; this is also a vital factor for structural breaks of China. In 2007-2011, the shale gas and oil boom influenced the world energy structure, due to new technologies for gas and oil drilling and extraction that found great reserves of total energy ( $\mathrm{Hu}$ et al. 2019). Finally, in 2014-2015 a dramatic decrease in world trade had a significant influence on China's economy and energy markets, with a sudden slowdown leading to sharp shocks.

\section{Robust analysis}

To test the robustness of our empirical analyses, we first take

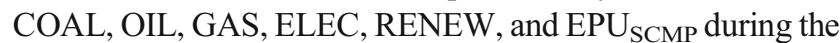
time period from January 2005 to October 2019 and reexamine the above analysis, as 2005 is the year that shale gas extraction began to play a momentous role in the world energy market. The results for PY, LM, and GLS-based unit 


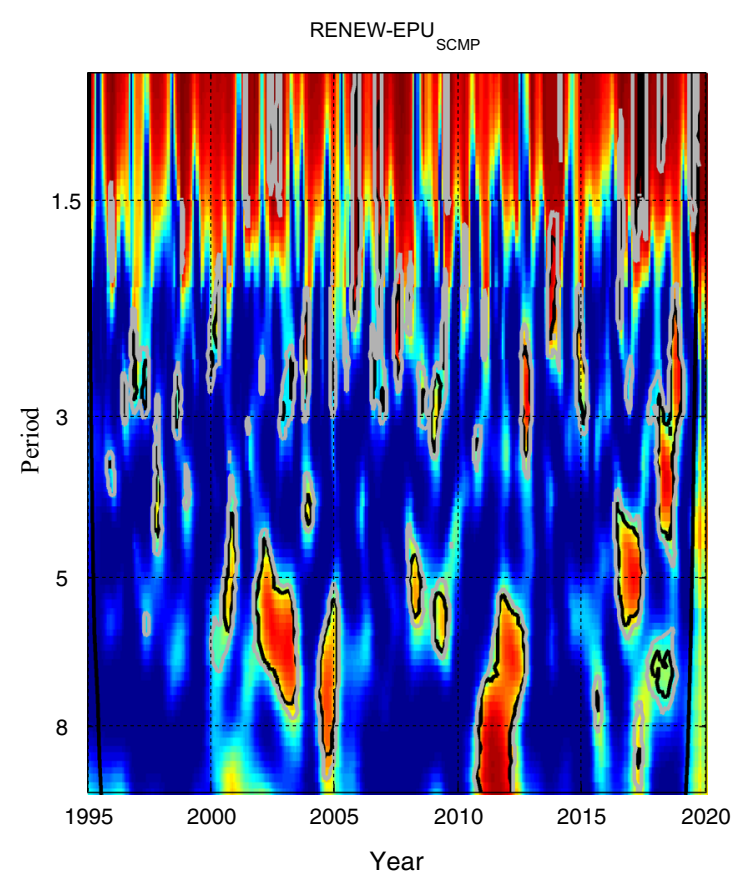

Fig. 6 RENEW-EPU $U_{S C M P}$ wavelet co-movements and phase-differences

root and cointegration tests with multiple structural breaks are not listed in our paper. ${ }^{15}$ The wavelet analyses appear in Figs. $7,8,9,10$, and 11 , which provide very similar conclusions like what we have explained for the time period of January 1995 to October 2019, again to obtain more evidence to support our results. In other words, we attain robust evidence that the series move in phase, and significantly dynamic causality is existed among energy production and $\mathrm{EPU}_{\mathrm{SCMP}}$.

We next utilize the Chinese EPU index based on mainland papers (EPU $\mathrm{MP}_{\text {P }}$ ) presented by Davis et al. (2019) to get more robust evidence of our results. We first make a comparison about $\mathrm{EPU}_{\mathrm{SCMP}}$ and $\mathrm{EPU}_{\mathrm{MP}}$; see Appendix 1. We find that $\mathrm{EPU}_{\mathrm{MP}}$ possesses more mainland newspapers and more economic/policy/uncertainty terms with Chinese characters than EPU $U_{\text {SCMP. }}$ The time period of EPU $U_{M P}$ is from January 1995 to October 2019. To further examine the robustness of our results, except for changing the economic policy uncertainty index from $\mathrm{EPU}_{\mathrm{SCMP}}$ to $\mathrm{EPU} \mathrm{MP}_{\mathrm{MP}}$, we also adopt the advanced cointegration test provided by Hatemi-J (2008) for a robust test on the cointegrated relationship among variables. The HatemiJ 2008 cointegration test is based on the Gregory and Hansen (1996) test by expanding former research to allow for two regime shifts. The timing of the breakpoints comes from the underlying data and not a priori information of the Gregory and Hansen 1996) test. Moreover, the Hatemi-J (2008) cointegration test places attention on the scale and power properties of all test statistics through Monte Carlo simulations, which can ensure all test statistics have small size distortion and good power properties versus the Gregory

$\overline{15}$ The details of robust analysis are available from the authors upon request.

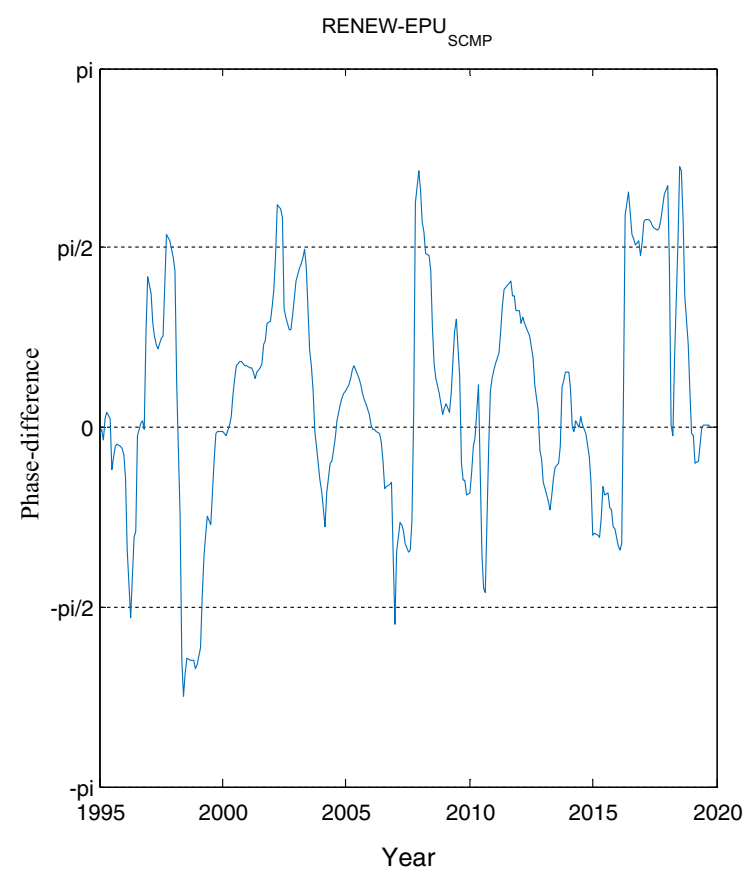

and Hansen (1996) test (Hatemi-J 2008). In Table 7, we again find that a cointegration relationship between $\mathrm{EPU}_{\mathrm{MP}}$ and OIL, COAL, GAS, ELEC and RENEW, respectively, which can strongly support our previous results. ${ }^{16}$ The structural breaks always focus on 1999, 2003-2006, 2008, and 2009, which are included in the earlier results.

We hence provide the wavelet co-movements and phase differences of $E P U_{M P}$ vs. COAL, EPU $U_{M P}$ vs. OIL, EPU vs. GAS, EPU $\mathrm{MP}_{\mathrm{MP}}$ vs. ELEC as well as EPU $\mathrm{MP}_{\mathrm{MP}}$ vs. RENEW. Similar patterns appear in Figs. 12, 13, 14, 15, to 16. Like the case of EPU $\mathrm{SCMP}_{\mathrm{S}}$ and energy production findings, the comovement between specific energy production and $E P U_{M P}$ is still clearer in the short run (high frequencies) versus that in the long run (low frequencies). However, we see stronger fluctuations between specific energy production and $\mathrm{EPU}_{\mathrm{MP}}$, compared to the EPU $\mathrm{SCMP}_{\mathrm{S}}$ findings. Some potential reasons arise. First, there are more newspaper sources for $\mathrm{EPU}_{\mathrm{MP}}$, which is more detailed and local than when EPU $\mathrm{SCMP}_{\text {only }}$ utilizes South China Morning Post. Second, a broader set of economic/policy/uncertainty terms with Chinese characteristics is added to the measure of EPU $\mathrm{MP}_{\mathrm{MP}}$. For energy market participants, more message sources and more local information imply easier access to accurate information, thus bringing about market fluctuations. Overall, through the robust tests, we find robust evidence of long-run co-movement among disparate energy productions and economic policy uncertainty.

\footnotetext{
$\overline{16}$ We also examine the cointegration test by Gregory and Hansen (1996). The findings are not presented in the paper to save space, and which are available for request. We do find that the results are similar with the earlier result, providing the long-term cointegration relationship exists in the variables.
} 

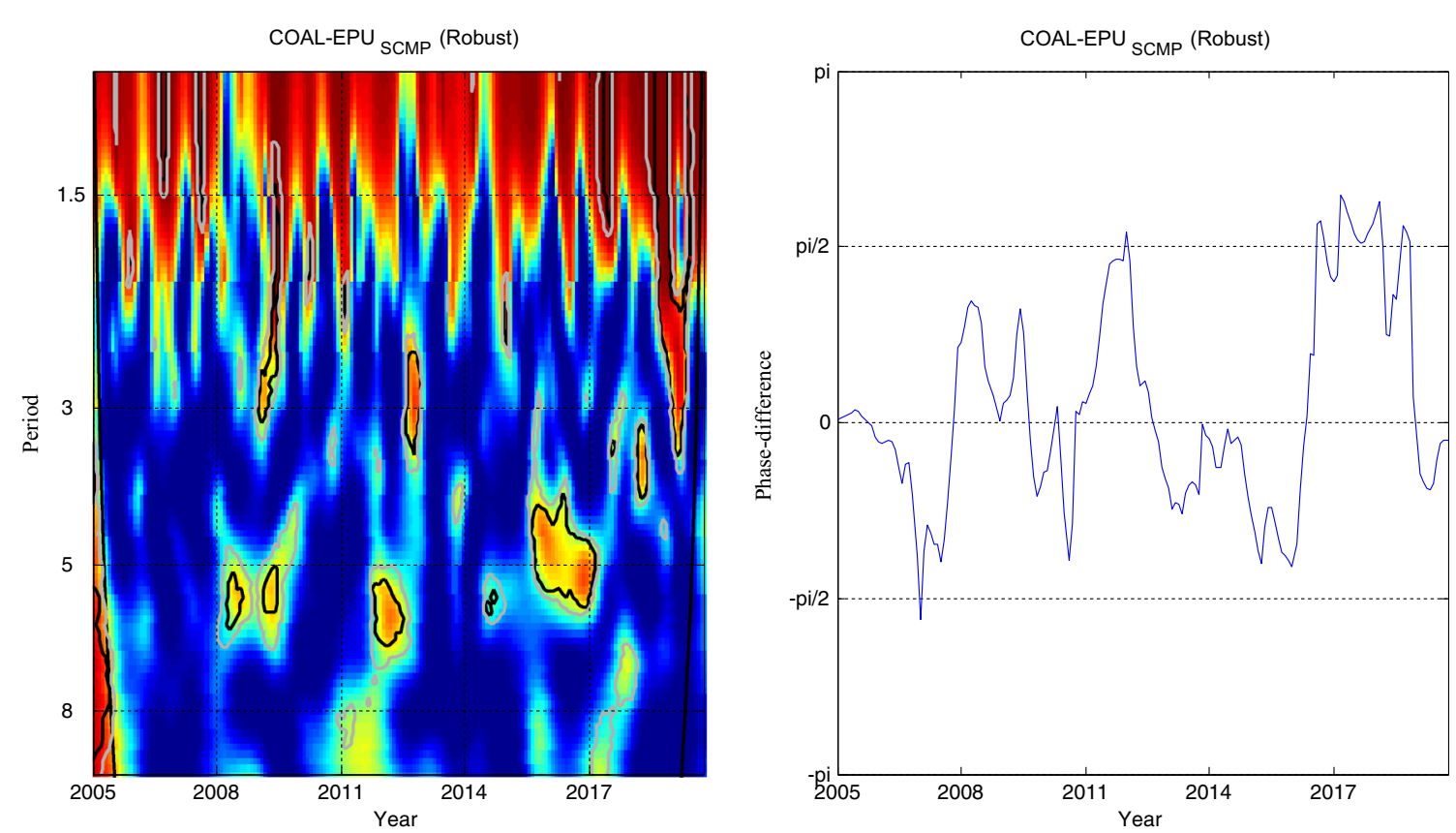

Fig. 7 Robust analysis of COAL-EPU $\mathrm{SCMP}_{\mathrm{S}}$ wavelet co-movements and phase-differences

\section{Policy implications}

We find an equilibrium relationship between economic policy uncertainty and energy production, when utilizing the Gregory and Hansen (1996) or Hatemi-J (2008) cointegration methods. From the results of wavelet co-movement combined with the phase difference analysis, we clearly see a positive causal co-movement relationship between the variables in the short run, but not in the long run. In accordance with the evidence, we offer a policy discussion as follows.

In the beginning, China's policymakers should place more attention on the short-run co-movement nexus between economic policy uncertainty and the energy market. At the same time, the phase difference showing a positive causal interaction can be a guide for the policymakers, meaning that economic policy uncertainty affects the energy market, and vice versa. In
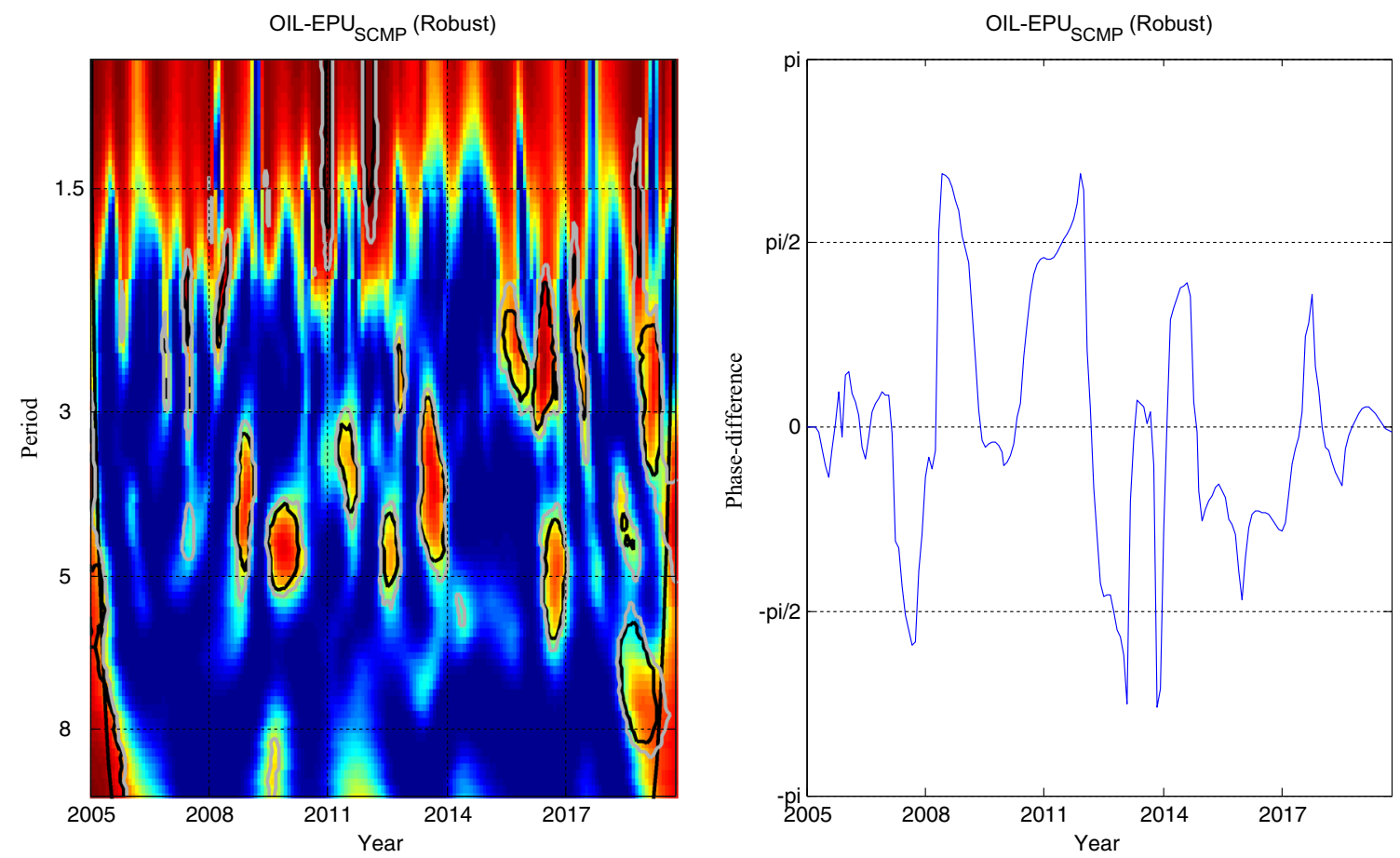

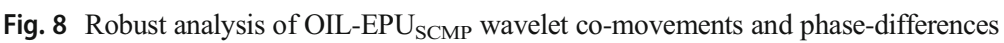



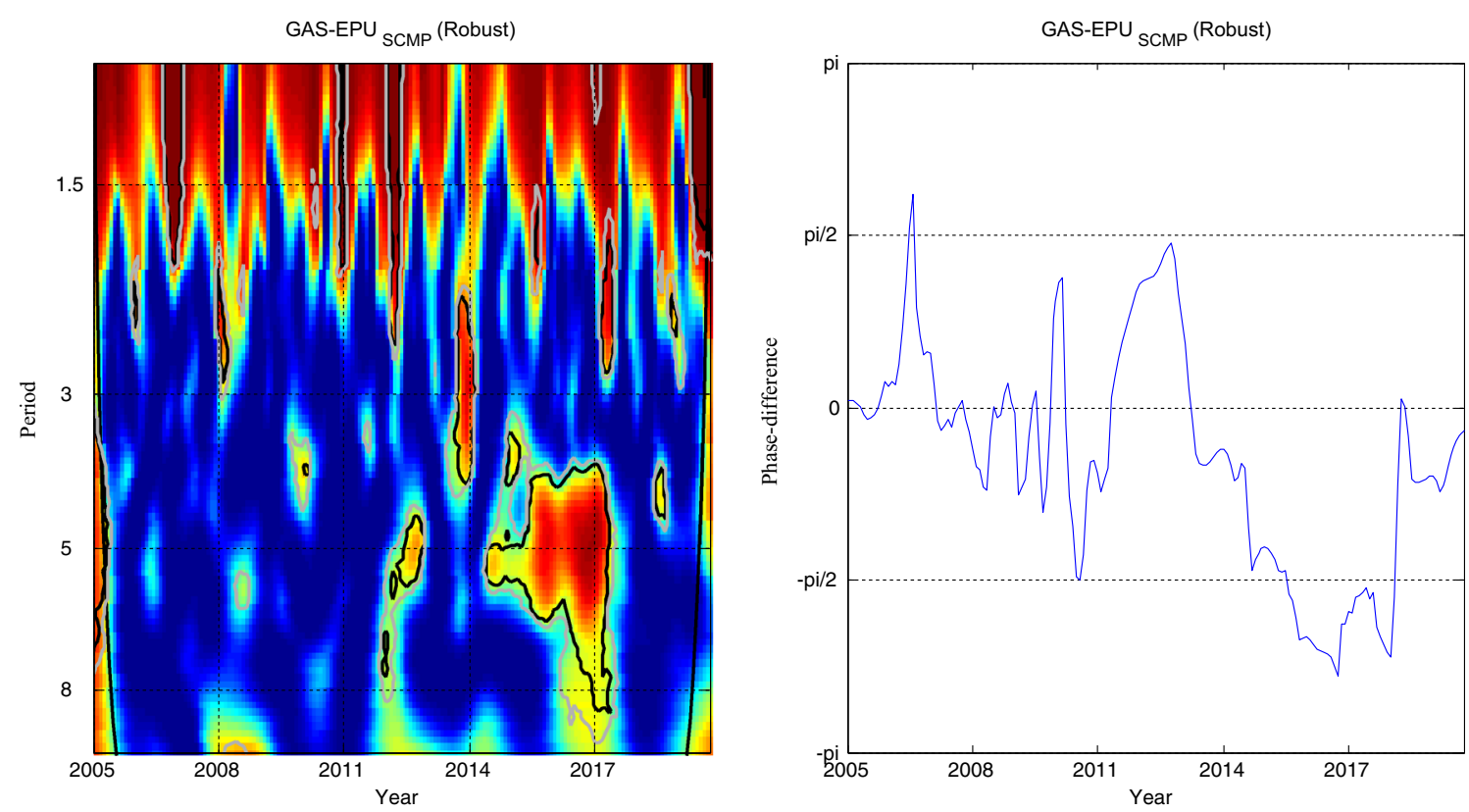

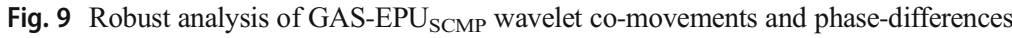

other words, excessive government intervention leads to fluctuations in energy markets, which in turn feed back into greater economic policy uncertainty. Next, China's authorities should maintain transparency and stability in policy formulation in order to reduce uncertainties. Through social media, journalism (such as Renmin Daily and Guangming Daily), tax allowance and exemption in energy sectors (Zhang et al. 2014), economic policy uncertainty can be mitigated more effectively. Furthermore, while the long-run co-movement relationship is not significant between variables, indicating in China that policymakers can ignore any long-term interference from both energy markets and economic policy formulation.
Considering the vital role of renewable energy, the China government should promote energy transformation of its renewable energy development system. It can initiate actions such as providing special funds to decrease renewable energy firms' financing constraints, offering tax incentives for renewable energy, and building a comprehensive supervisory platform to create a more effective and efficient environment for the renewable energy industry. Overall, the China government should place more attention on renewable energy under high uncertainty, covering energy resources' endowment, technical improvement, and industrial growth stages.
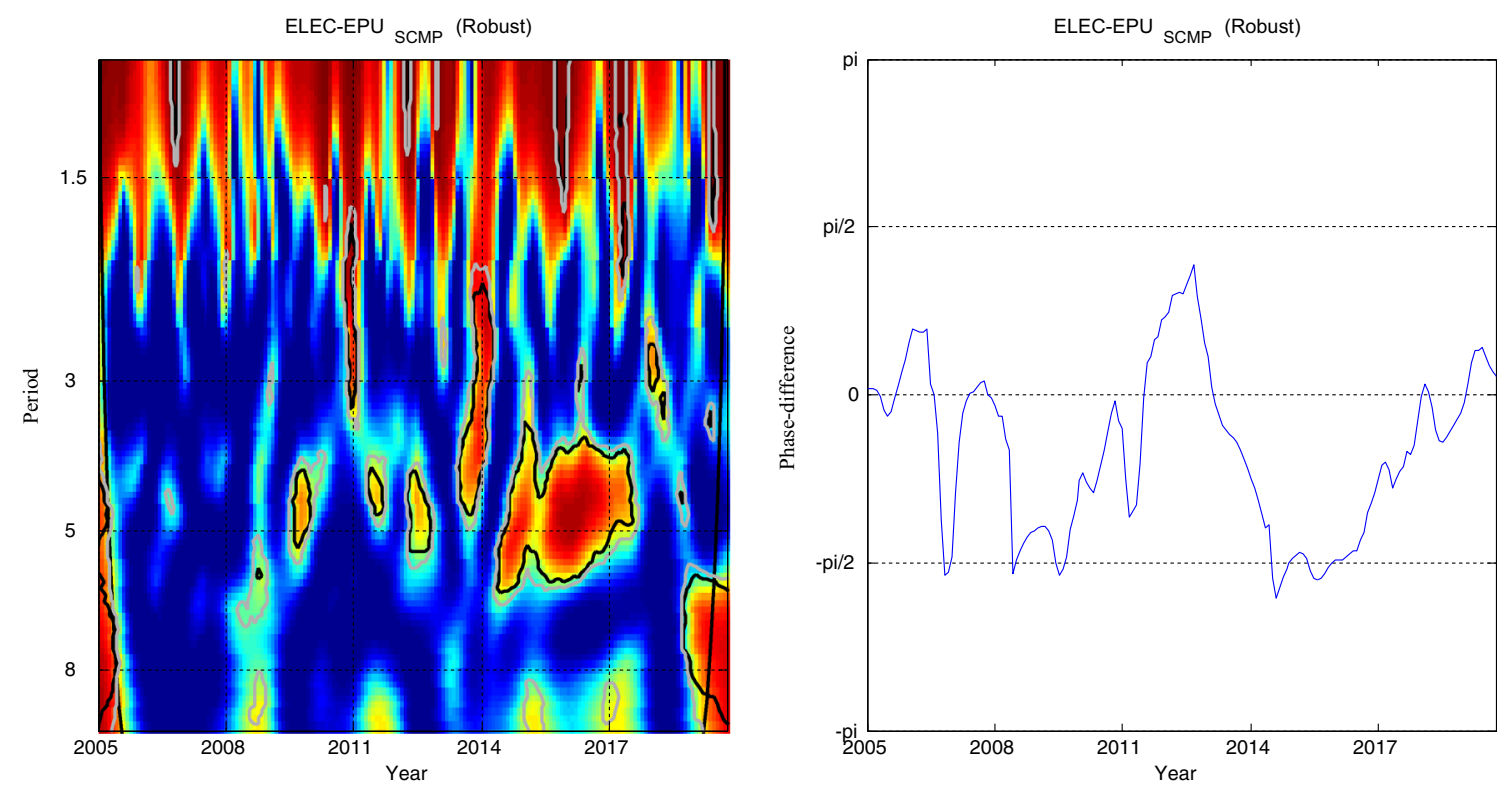

Fig. 10 Robust analysis of ELEC-EPU $\mathrm{SCMP}_{\mathrm{S}}$ wavelet co-movements and phase-differences 

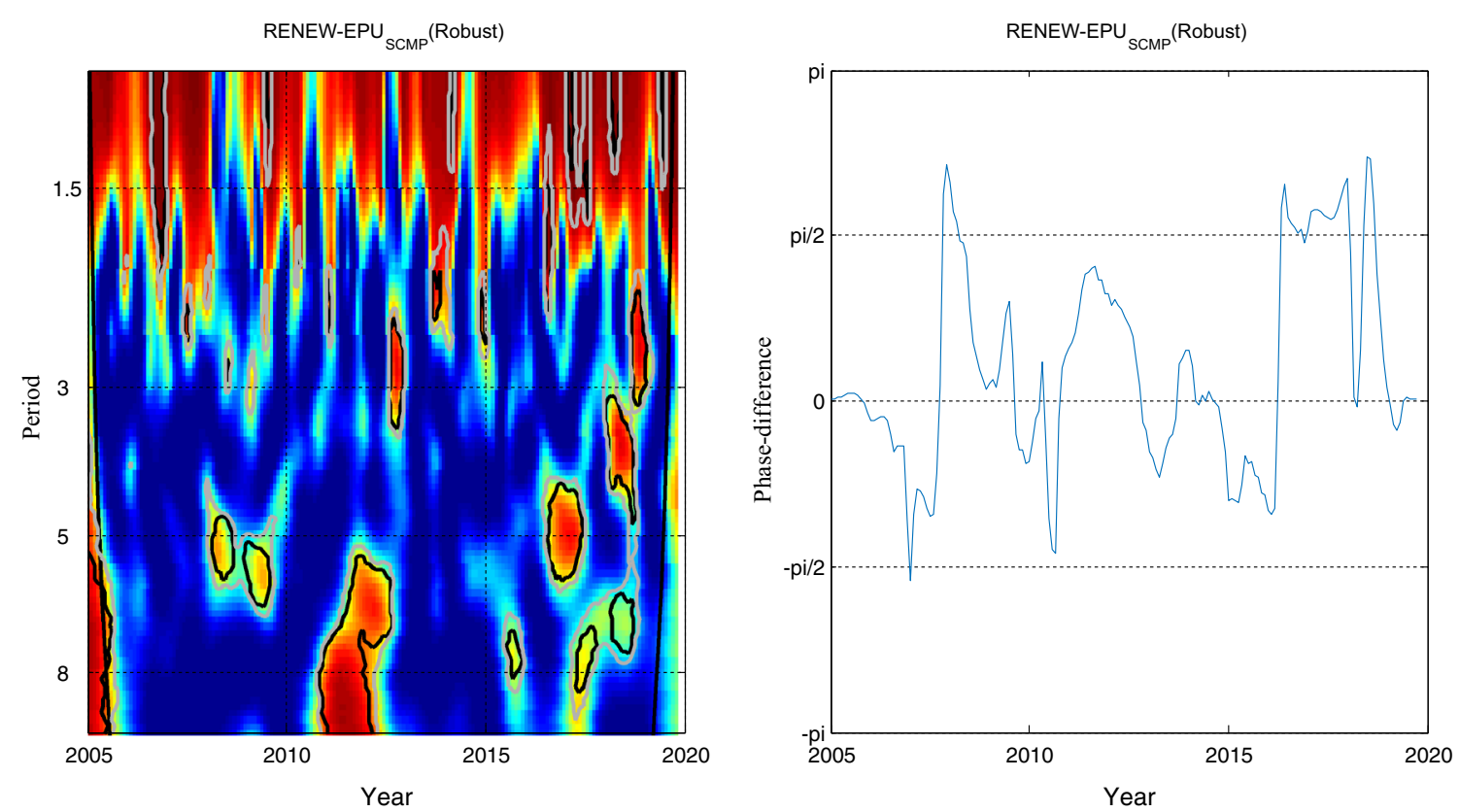

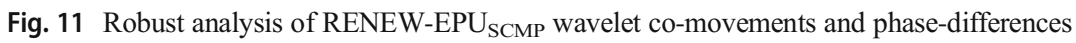

Second, a clearer co-movement and positive causal relationship in the short run also bring critical implications for energy market participants in China, such as for China National Petroleum Corporation as well as China PetroChemical Corporation. These energy market participants not only need to focus on economic policy, which leads to fluctuations in the energy market, but must also consider the influence of volatility in the energy market on economic policy uncertainty. Since economic policy uncertainty can stimulate energy production, energy market participants should pay close attention to authoritative newspapers in China, like People's Daily, Guangming Daily, and South China Morning Post, so as to instantly grasp fluctuating messages. Given the co-movements between variables as we have presented, energy market participants in China can easily understand the nexus, make important portfolio allocation decisions (Mensi et al. 2014), precisely screen for useful energy information, and reduce their risks from market uncertainties.
Finally, as energy demanders, most Chinese citizens should take note of those domestic authoritative newspapers and prominent media as mentioned earlier in order to grasp important messages of uncertainties and energy shocks. For instance, once newspapers report information about an unstable economic policy, Chinese citizens as well as energy demanders could take personal actions such as buying more energy products, which may then bring about greater increases in energy prices and further raise economic policy uncertainty. In addition, as a large country that considers both population and resources, fluctuations in China's energy market will spur a change to energy supply and demand, which will then drive volatility and uncertainty of economic policies promoted by the China government. Similarly, Chinese citizens should only pay attention to the short-term interaction between variables, because of weak co-movements in energy production and economic policy over the long term.

Table 7 HJ time-series cointegration test with two structural breaks

\begin{tabular}{|c|c|c|c|c|c|c|c|c|c|c|}
\hline \multirow[t]{2}{*}{ Tests } & \multicolumn{2}{|l|}{ COAL } & \multicolumn{2}{|l|}{ OIL } & \multicolumn{2}{|l|}{ GAS } & \multicolumn{2}{|l|}{ ELEC } & \multicolumn{2}{|l|}{ RENEW } \\
\hline & T-statistic & Break dates & T-statistic & Break dates & T-statistic & Break dates & T-statistic & Break dates & T-statistic & Break dates \\
\hline$A D F^{*}$ & -4.799 & $\begin{array}{l}200411 \\
200605\end{array}$ & -4.764 & $\begin{array}{l}200302 \\
200706\end{array}$ & $-8.711^{*}$ & $\begin{array}{l}200402 \\
\mathbf{2 0 0 8 0 7}\end{array}$ & $-8.361^{*}$ & $\begin{array}{l}\mathbf{2 0 0 3 1 1} \\
200901\end{array}$ & $-8.240^{*}$ & $\begin{array}{l}200412 \\
\mathbf{2 0 0 9 0 5}\end{array}$ \\
\hline$Z_{t}^{*}$ & $-9.835^{*}$ & $\begin{array}{l}200312 \\
200604\end{array}$ & $-7.336^{*}$ & $\begin{array}{l}199911 \\
200805\end{array}$ & $-8.972^{*}$ & $\begin{array}{l}200401 \\
200811\end{array}$ & $-8.641^{*}$ & $\begin{array}{l}200308 \\
200811\end{array}$ & $-8.281^{*}$ & $\begin{array}{l}200412 \\
\mathbf{2 0 0 9 0 4}\end{array}$ \\
\hline$Z_{\alpha}^{*}$ & $-146.913^{*}$ & $\begin{array}{l}200312 \\
200603\end{array}$ & $-82.712^{*}$ & $\begin{array}{l}199911 \\
200805\end{array}$ & $-123.860^{*}$ & $\begin{array}{l}200401 \\
200811\end{array}$ & $-118.280^{*}$ & $\begin{array}{l}200308 \\
200811\end{array}$ & $-111.007^{*}$ & $\begin{array}{l}200312 \\
200905\end{array}$ \\
\hline
\end{tabular}

The entries in bold are structural breaks with high frequent appearance

Notes: ${ }^{*}$ denotes that the no cointegration hypothesis is rejected at the $5 \%$ level. The critical value of HJ test is available in Hatemi-J (2008), Table 1 

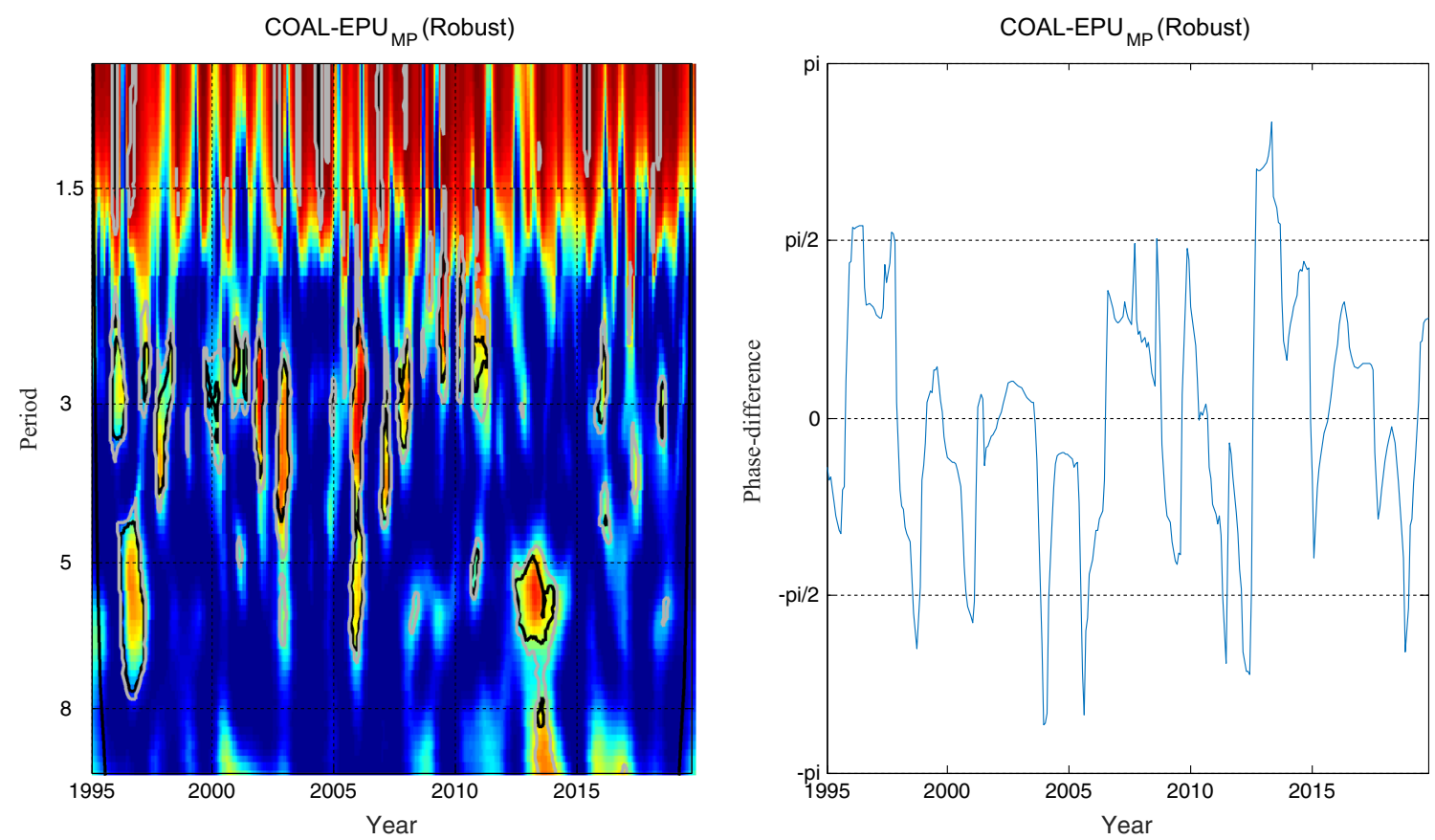

Fig. 12 Robust analysis of COAL-EPU $\mathrm{MP}_{\mathrm{M}}$ wavelet co-movements and phase-differences

China's policymakers and market participants should overall be aware of the co-movement and positive casual interactions between economic policy and the energy market. Doing so will contribute to making proper subsequent decisions.

\section{Concluding remarks}

Though economic policy uncertainty is widely taken as a vital component affecting global energy demand and supply, there has been limited research that particularly concentrates on the nexus among disparate energy productions and economic policy uncertainty. Compared with past literature that exclusively conducts investigations in the time domain, we examine the relationship among disparate energy productions and economic policy uncertainty via a dynamic co-movement in both time and frequency domains. We employ five types of energy productions, coal, oil, natural gas, electricity and renewable one, covering the sample period from January 1995 to October 2019.
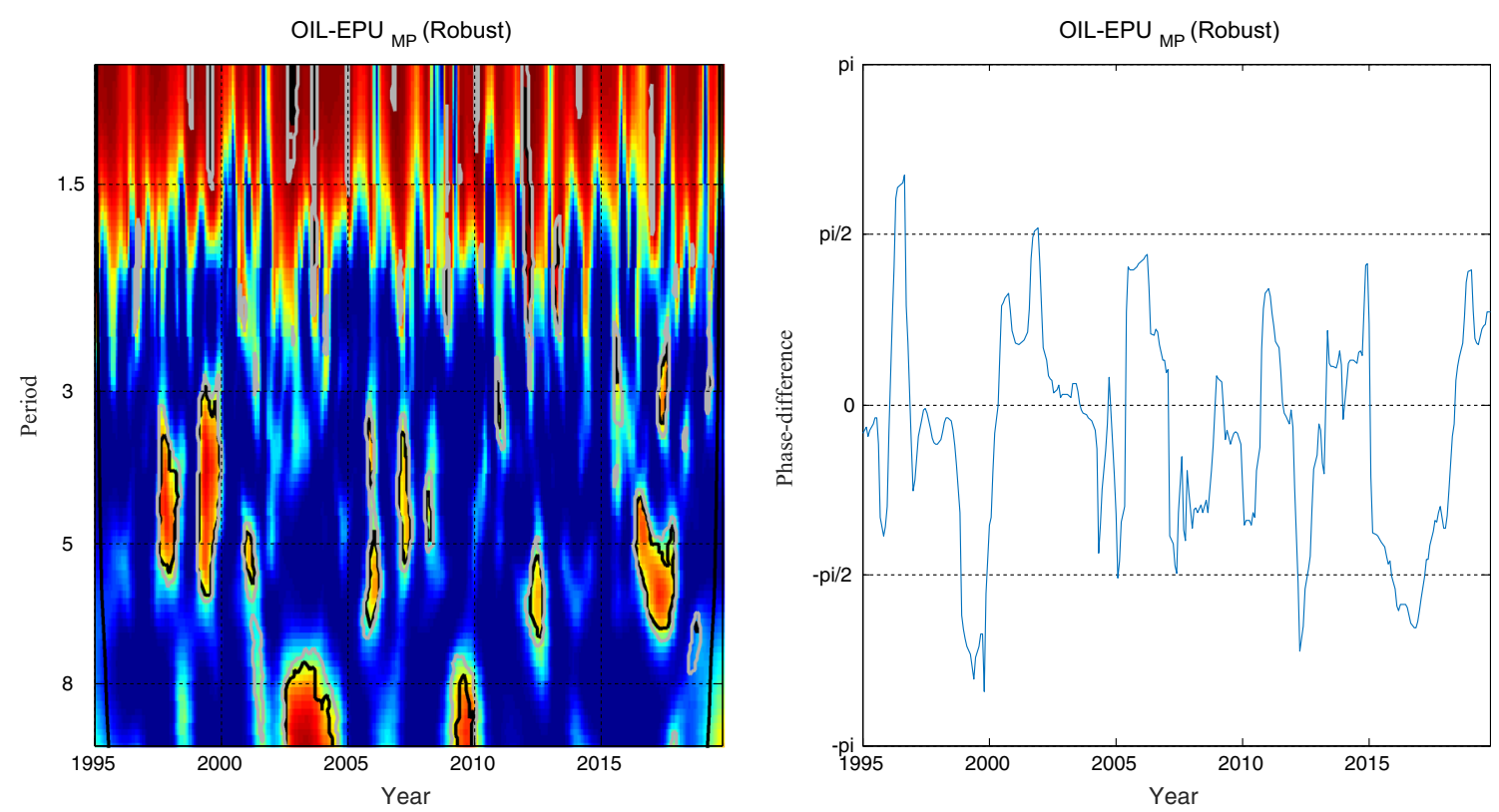

Fig. 13 Robust analysis of OIL-EPU $\mathrm{MP}_{\mathrm{P}}$ wavelet co-movements and phase-differences 

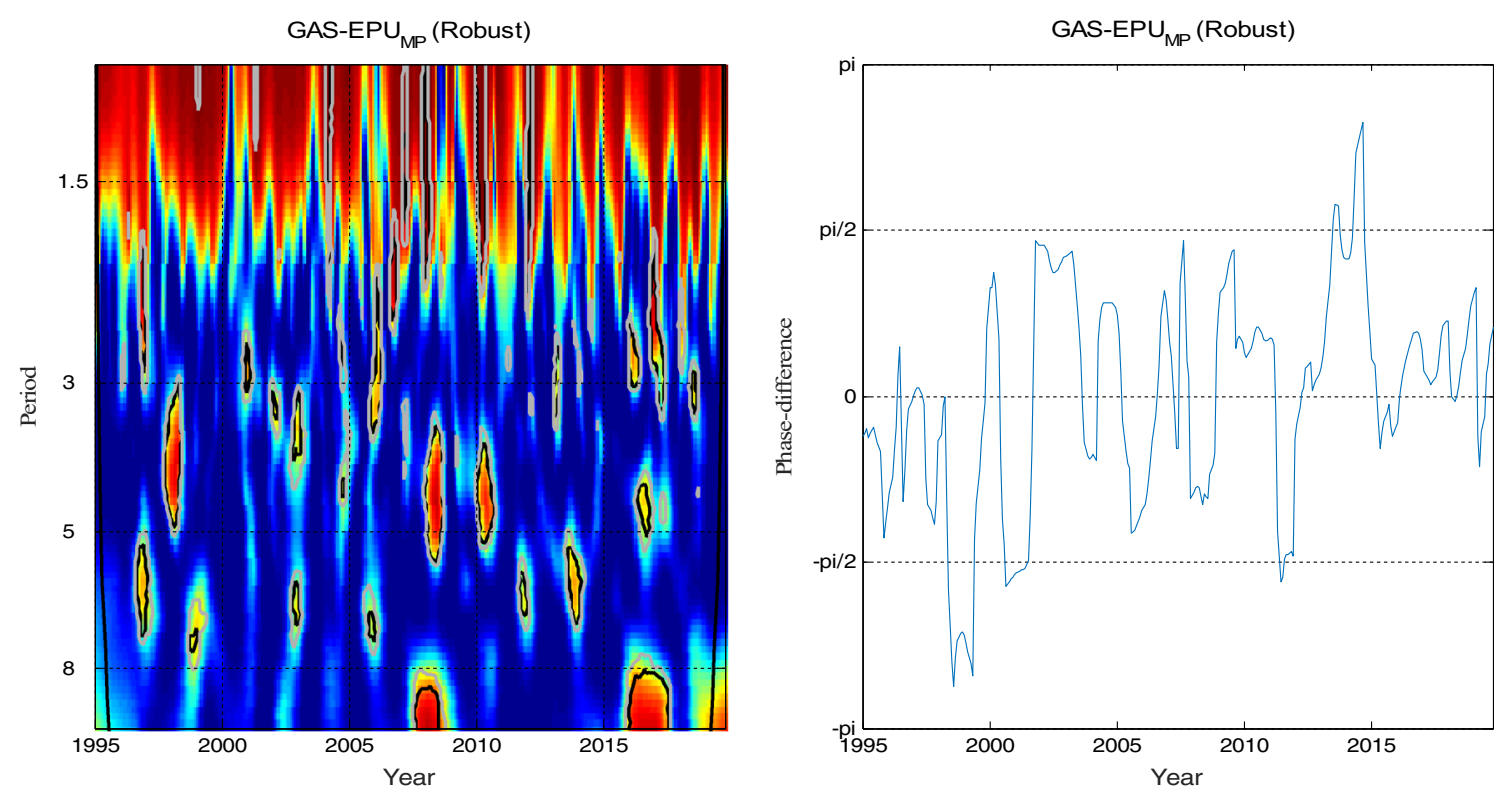

Fig. 14 Robust analysis of GAS-EPU $\mathrm{MP}_{\mathrm{MP}}$ wavelet co-movements and phase-differences

The empirical results show that there are stationary property and cointegration nexus between energy production and economic policy uncertainty. To gain more evidence of time and frequencies for the series, we also utilize an advanced method of wavelet analysis to observe dynamic co-movements and the causal relationship among the variables. We also present robust analysis denoting a co-movement exists among disparate energy productions and economic policy uncertainty. Generally, we see the sample have a strong level of co-movement in high frequencies (short-run fluctuations); however, the evidence for low frequencies (long-run fluctuations) is relatively weaker. We also validate a dynamic causal nexus among disparate energy productions and economic policy uncertainty following a positive causality. Overall, our results raise a significant issue about the role of economic policy uncertainty as a driver of risk transmissions through energy markets and also offer an opportunity for authorities to promote strategies to handle energy risks, according to the various factors of economic policy uncertainty.
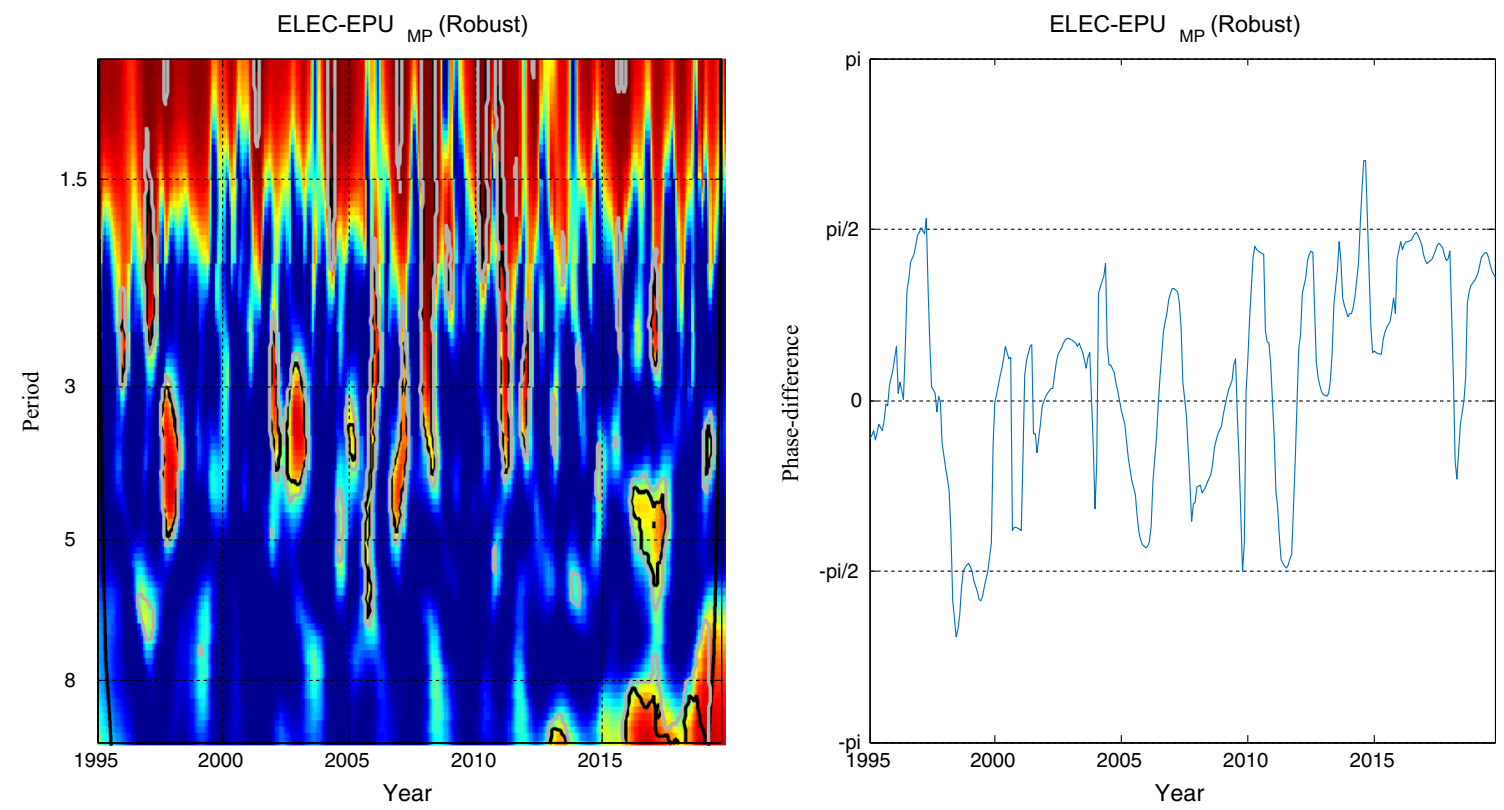

Fig. 15 Robust analysis of ELEC-EPU $\mathrm{MP}_{\mathrm{M}}$ wavelet co-movements and phase-differences 

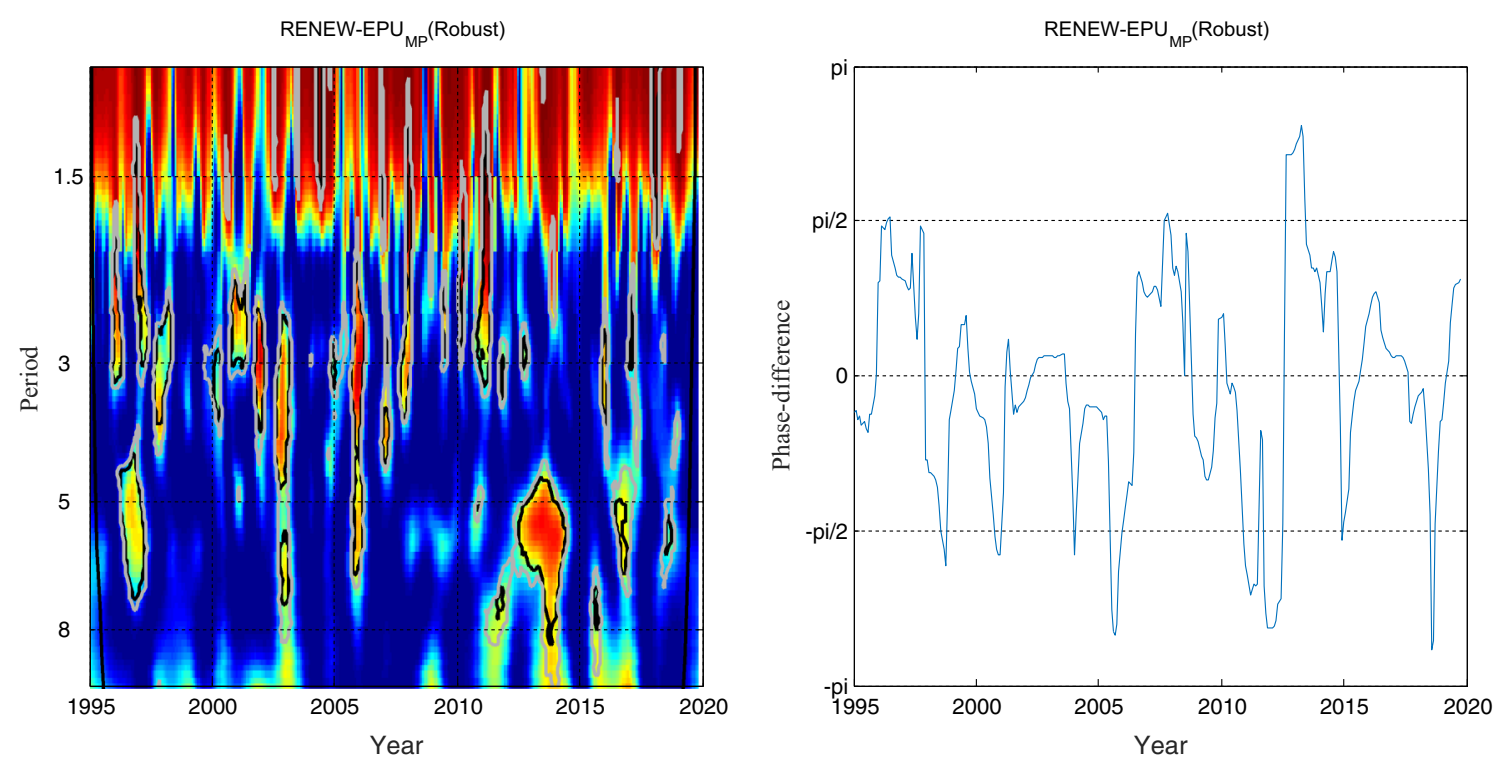

Fig. 16 Robust analysis of RENEW-EPU $\mathrm{MP}_{\text {wavelet co-movements and phase-differences }}$

\section{Appendix 1}

Comparisons of the two economic policy uncertainty indices.

China EPU Index based on the South China Morning Post

China EPU Indices based on Domestic Newspapers (EPU $\mathrm{MP})$ $\left(\mathrm{EPU}_{\mathrm{SCMP}}\right)$

Definition

The economic policy uncertainty indices are constructed on an automated search process to track the frequency terms; i.e., economic policy-, uncertainty-, and regulation-related words through the main newspapers. Economic policy uncertainty includes the influence of economic policies on investment, consumption, and employment of enterprises and individuals, as well as on macroeconomic, capital and energy markets, and so on. Both indices follow the newspaper-based techniques in "Measuring Economic Policy Uncertainty" by Baker et al. (2016).

Category Uncertainty Uncertain; uncertainty; not certain; unsure; not sure; hard to tell; unpredictable; unknown.

Economics Economy; economic; business.

Policy Policy; spending; budget; political; interest rates; reform; government; Beijing; authorities; tax; regulation; regulatory; central bank; People's Bank of China; deficit; WTO.

\section{Newspaper source \\ Computational process}

\section{South China Morning Post}

To calculate an economic policy uncertainty index for China, Baker et al. (2016) structured a scaled frequency count of articles about policy-related economic uncertainty through Hong Kong's leading English-language newspaper, i.e., the South China Morning Post (SCMP).

First, they identified SCMP articles about the three term sets of Economic, Policy, and Uncertainty. Second, they utilized these terms in an automated search on a monthly frequency, through every SCMP article published since 1995. Next, they divided the monthly frequency count by the number of all SCMP articles in the same month. They thus standardized the result to a mean value of 100 from January 1995 to the present.
Uncertain; uncertainty; not certain; unsure; not sure; hard to tell; unpredictable; unknown.

Economy; economic; business.

Fiscal; monetary; China Securities Regulatory Commission; Ministry of Finance; People's Bank of China; National Development and Reform Commission; opening-up; reform; Ministry of Commerce; legislation; tax; national bonds; government debt; central bank; Ministry of Commerce; tariff; governmental deficit.

\section{Renmin Daily and Guangming Daily}

Utilizing the terms with Chinese properties and the corresponding English translations, Davis' team first tracked for monthly counts of articles that include at least one term in each of three term sets: Economics, Policy, and Uncertainty. Second, they measured the initial monthly data counted by the entire number of articles for the same newspaper and month. Third, the team divided the time into three periods: the central planning era (1949-1978), the reform and opening-up period (1979-1999), and the globalization era (2000 onwards). Additionally, they normalized each newspaper's monthly series to have a unit standardization. Fourth, they calculated the simple average of the results over newspapers by month. Finally, they standardized every period's index value to an average of 100 . 
Author contributions Wei Wei: Set up the theoretical frame and review the relevant literature.

Haiqing $\mathrm{Hu}$ : Data collection and quantitative investigation.

Chun-Ping Chang: Propose the research idea, motivate and revise the whole paper.

Data availability Yes, by requested.

\section{Declarations}

Ethical approval Not applicable.

Consent to participate and consent for publication All the authors listed have approved the manuscript that is enclosed, and consent to participate and publish it if paper is accepted.

Conflict of interest The authors declare no competing interests.

\section{References}

Abaidoo R (2019) Corporate performance volatility and adverse macroeconomic conditions. J Finan Econ Policy 11(4):533-547

Adedoyin FF, Zakari A (2020) Energy consumption, economic expansion, and $\mathrm{CO}_{2}$ emission in the UK: the role of economic policy uncertainty. Sci Total Environ 738:140014. https://doi.org/10. 1016/j.scitotenv.2020.140014

Aguiar-Conraria L, Soares MJ (2011) Oil and the macroeconomy: using wavelets to analyze old issues. Empir Econ 40(3):645-655

Aguiar-Conraria L, Magalhâes P, Soares MJ (2012) Cycles in politics: wavelet analysis of political time series. Am J Polit Sci 56(2):500 518

Aloui R, Gupta R, Miller SM (2016) Uncertainty and crude oil returns. Energy Econ 55:92-100

Antonakakis N, Chatziantoniou I, Filis G (2014) Dynamic spillovers of oil price shocks and economic policy uncertainty. Energy Econ 44: 433-447

Apergis N, Payne JE (2010) Renewable energy consumption and economic growth: evidence from a panel of OECD countries. Energy Policy 38(1):656-660

Arora V, Lieskovsky J (2014) Natural gas and U.S. economic activity. Energy J 35(3):167-182

Bachmann R, Elstner S, Sims E (2013) Uncertainty and economic activity: evidence from business survey data. Am Econ J 5(2):217-249

Baker SR, Bloom N (2013) Does uncertainty reduce growth? Using disasters as natural experiments (No. w19475). National Bureau of Economic Research, Washington

Baker SR, Bloom N, Davis SJ (2016) Measuring economic policy uncertainty. Q J Econ 131(4):1593-1636

Barro CP, Gil-Alana LA, Payne JE (2011) An analysis of oil production by OPEC countries: persistence, breaks, and outliers. Energy Policy 39:442-453

Barro CP, Gil-Alana LA, Wanke P (2016) Energy production in Brazil: Empirical facts based on persistence, seasonality and breaks. Energy Econ 54:88-95

Bekiros S, Gupta R, Paccagnini A (2015) Oil price forecast ability and economic uncertainty. Econ Lett 132:125-128

Benhmad F (2012) Modeling nonlinear Granger causality between the oil price and US dollar: a wavelet based approach. Econ Model 29(4): $1505-1514$

Bergman M, Bordo M, Jonung L, (1998). Historical evidence on business cycles: the international experience. In: Conf Series; Federal Reserve Bank of Boston, 42, 65-119.
Bloch H, Rafiq S, Salim R (2012) Coal consumption, $\mathrm{CO}_{2}$ emission and economic growth in China: empirical evidence and policy response. Energy Econ 34:518-528

Bloom N (2009) The impact of uncertainty shocks. Econometrica 77(3): $623-685$

BP. (2016) BP statistical review of world energy. https://www.bp.com/ zh_cn/china/reports-and-publications/bp_2016.html. Accessed 6 Jun 2016

Brogaard J, Detzel A (2015) The asset-pricing implications of government economic policy uncertainty. Manag Sci 61(1):3-18

Carrión-i-Silvestre JL, Kim D, Perron P (2009) GLS-based unit root tests with multiple structural breaks under both the null and the alternative hypotheses. Economic Theory 25(6):1754-1792

Chang CP, Lee CC (2008) Are per capita carbon dioxide emissions converging among industrialized countries? New time series evidence with structural breaks. Environ Dev Econ 13(4):497-515

Chang CP, Lee CC (2015) Do oils pot and futures prices move together? Energy Econ 50:379-390

Chang CP, Berdiev AN, Lee CC (2013) Energy exports, globalization and economic growth: the case of south Caucasus. Econ Model 33(2):333-346

Chen WY, Xu RN (2010) Clean coal technology development in China. Energy Policy 38:2123-2130

Chen PF, Lee CC, Zeng JH (2014) The relationship between spot and futures oil prices: do structural breaks matter? Energy Econ 43: 206-217

Chen B, Han MY, Peng K, Zhou SL et al (2018a) Global land-water nexus: agricultural land and freshwater use embodied in worldwide supply chains. Sci Total Environ 613:931-943

Chen S, Zhang Q, Wang G, Zhu L, Li Y (2018b) Investment strategy for underground gas storage facilities based on real option model considering gas market reform in China. Energy Econ 70:132-142

Chen B, Wang XB, Li YL, Yang Q, Li JS (2019) Energy-induced mercury emissions in global supply chain networks: structural characteristics and policy implications. Sci Total Environ 670:87-97

Dai Y, Zhang JW, Yu XZ et al (2017) Causality between economic policy uncertainty and exchange rate in China with considering quantile differences. heor Appl Econ 24(3):29-38

Davis, S. J., Liu, D. Q., Sheng, X. G. S., (2019). Economic policy uncertainty in China since 1949: The view from mainland newspapers. Working paper.

Dong MY, Chang CP, Gong Q, Chu Y (2019) Revisiting global economic activity and crude oil prices: A wavelet analysis. Econ Model 78: 134-149

Edenhofer O (2015) King coal and the queen of subsidies. Science 349(6254):1286-1287

EIA, (2015). International Energy Data and Analysis. https://energy. gov/sites/prod/files/2016/04/f30/China_International_Analysis_ US. pdf. Accessed 30 Apr 2015

EIA, (2016). International Energy Outlook 2016 With Projections to 2040. United States Energy Information. http://www.eia.gov/ outlooks/ieo/. Accessed 1 May 2016

Fang Z, Chen Y (2017) Human capital and energy in economic growthEvidence from Chinese provincial data. Energy Econ 68:340-358

Friedl B, Getzner M (2003) Determinants of CO2 emissions in a small open economy. Ecol Econ 45(1):133-148

Gregory AW, Hansen BE (1996) Residual-based tests for cointegration in models with regime shifts. J Econ 70(1):99-126

Guan D, Su X, Zhang Q, Peters GP et al (2014) The socioeconomic drivers of China's primary $\mathrm{PM}_{25}$ emissions. Environ Res Lett 9:10-19

Guan D, Meng J, Reiner DM, Zhang N, Shan Y, Mi Z, Shao S, Liu Z, Zhang Q, Davis SJ (2018) Structural decline in China's $\mathrm{CO}_{2}$ emissions through transitions in industry and energy systems. Nat Geosci 11:551-555

Gupta K, Krishnamurti C (2018) Do macroeconomic conditions and oil prices influence corporate risk-taking? J Corp Finan 53:65-86 
Hafezalkotob A (2018) Direct and indirect intervention schemas of government in the competition between green and non-green supply chains. J Clean Prod 170:753-772

Hailemariam A, Smyth R, Zhang XB (2019) Oil prices and economic policy uncertainty: Evidence from a nonparametric panel data model. Energy Econ 83:40-51

Hamilton J (1983) Oil and macroeconomy since World War II. J Polit Econ 91(2):47-65

Hatemi-J A (2008) Tests for cointegration with two unknown regime shifts with an application to financial market integration. Empir Econ 35(3):497-505

Herrerias MJ, Joyeux R, Girardin E (2013) Short- and long-run causality between consumption and economic growth: evidence across regions in China. Appl Energy 112:1483-1492

Hsu CL, Chang CY, Yansritakul C (2017) Exploring purchase intention of green skincare products using the theory of planned behavior: testing the moderating effects of country of origin and price sensitivity. J Retail Consum Serv 34:145-152

Hu HQ, Wei W, Chang CP (2019) Do shale gas and oil productions move in convergence? An investigation using unit root tests with structural breaks. Econ Model 77(3):21-33

International Energy Agency, IEA (2018) Renewables 2018 Analysis and forecasts to 2023. https://www.iea.org/reports/ renewables-2018

Jaiswal D, Kant R (2018) Green purchasing behaviour: a conceptual framework and empirical investigation of Indian consumers. $J$ Retail Consum Serv 41:60-69

Jiang YH, Zhu ZX, Tian GY, Nie H (2019) Determinants of within and cross-country economic policy uncertainty spillovers: Evidence from US and China. Financ Res Lett 31:195-206

Kan S, Chen B, Chen G (2019) Worldwide energy use across global supply chains: decoupled from economic growth? Appl Energy 250:1235-1245

Kang W, Gracia FPD, Ratti RA (2017a) Oil price shocks, policy uncertainty, and stock returns of oil and gas corporations. J Int Money Financ 70:344-359

Kang W, Ratti RA, Vespignani JL (2017b) Oil price shocks and policy uncertainty: new evidence on the effects of US and non-US oil production. Energy Econ 66:536-546

Khandokar I, Serletis A (2018) Economic policy uncertainty and real output: evidence from the G7 countries. Appl Econ 50(39):4222-4233

Kinnon MMA, Brouwer J, Samuelsen S (2018) The role of natural gas and its infrastructure in mitigating greenhouse gas emissions, improving regional air quality, and renewable resource integration. Prog Energy Combust Sci 64:62-92

Kirikkaleli D, Adedoyion FF, Bekun FV (2020) Nuclear energy consumption and economic growth in the UK: evidence from wavelet coherence approach. J Public Aff 21:1-11. https://doi.org/10.1002/pa/2130

Lee CC (2013) Insurance and real output: the key role of banking activities. Macroecon Dyn 17:235-260

Lee CC, Chang CP (2008) Tourism development and economic growth: a closer look at panels. Tour Manag 29(1):180-192

Lee J, Strazicich MC (2003) Minimum Lagrange multiplier unit root test with two structural breaks. Rev Econ Stat 85(4):1082-1089

Lee J, Strazicich MC (2004) Minimum LM unit root test with one structural break. Econ Bull 33(4):2483-2492

Li K, Lin B (2016) Impact of energy technology patents in China: evidence from a panel cointegration and error correction model. Energy Policy 89:214-223

Li JS, Chen B, Chen GQ, Wei WD, Wang XB, Ge JP, Dong KQ, Xia HH, Xia XH (2017) Tracking mercury emission flows in the global supply chains: a multi-regional input-output analysis. J Clean Prod 140: 1470-1492

Linn J, Muehlenbachsn L (2018) The heterogeneous impacts of low natural gas prices on consumers and the environment. $J$ Environ Econ Manag 89:1-28
Ma, D., (2015). Rebalancing China's energy strategy. Paulson Pap Energy Environ.

Ma R, Chen B, Guan C, Meng J, Zhang B (2018) Socioeconomic determinants of China's growing CH4 emissions. J Environ Manag 228: $103-116$

Mahardika H, Thomas D, Ewing M, Japutra A (2019) Predicting consumers' trial/adoption of new technology: revising the behavioral expectations - behavioral intentions debate. Int Rev Retail Distrib Consum Res 29(1):99-117

Meng J, Liu J, Xu Y, Guan D et al (2016) Globalization and pollution: tele-connecting local primary $\mathrm{PM}_{2.5}$ emissions to global consumption. Proc R Soc London, Series A 472:2195-2197

Meng J, Mi Z, Guan D, Li J, Tao S et al (2018) The rise of south-south trade and its effect on global $\mathrm{CO}_{2}$ emissions. Nat Commun 9(1):18-71

Mensi W, Hammoudeh S, Reboredo JC, Nguyen DK (2014) Do global factors impact BRICS stock markets? A quantile regression approach. Emerg Mark Rev 19:1-17

Nathaniel S, Nwodo O, Sharma G, Shah M, (2020). Renewable energy, urbanization, and ecological footprint linkage in CIVETS. Environ Sci Pollut Res 1-14.

Ng S, Perron P (1995) Unit root tests in ARMA models with datadependent methods for the selection of the truncation lag. $J \mathrm{Am}$ Stat Assoc 90(429):268-281

Oberschelp C, Pfister S, Raptis C, Hellweg S (2019) Global emission hotspots of coal power generation. Nat Sustain 2:113-121

Olanipekun I, Olasehinde-Williams G, Akadiri S (2019) Gasoline prices and economic policy uncertainty: what causes what, and why does it matter: evidence from 18 selected countries. Environ Sci Pollut Res 26(15): $15187-15193$

Pan XF, Ai BW, Li CY, Pan XY et al (2019) Dynamic relationship among environmental regulation, technological innovation and energy efficiency based on large scale provincial panel data in China. Technol Forecast Soc Change 144:428-435

Perron P (1989) The great crash, the oil price shock and the unit root hypothesis. Econometrica 57(6):1361-1401

Perron P, Yabu T (2009) Testing for shifts in trend with an integrated or stationary noise component. J Bus Econ Stat 27(3):369-396

Plank B, Eisenmenger N, Schaffartzik A, Wiedenhofer D (2018) International trade drives global resource use: a structural decomposition analysis of raw material consumption from1990-2010. Environ Sci Technol 52:4190-4198

Qin QD, Li X, Li L, Zhen W et al (2017) Air emissions perspective on energy efficiency: an empirical analysis of China's coastal areas. Appl Energy 85:604-614

Sari R, Ewing BT, Soytas U (2008) The relationship between disaggregate energy consumption and industrial production in the United States: an ARDL approach. Energy Econ 30(5):2302-2313

Schreiber T, Schmitz A (1996) Improved surrogate data for nonlinearity tests. Phys Rev Lett 77(4):635-638

Sen A (2003) On unit-root tests when the alternative is a trend-break stationary process. J Bus Econ Stat 21(1):174-184

Shah IH, Hiles C, Morley B (2018) How do oil prices, macroeconomic factors and policies affect the market for renewable energy? Appl Energy 215(1):87-97

Shahbaz M, Khraief N, Mahalik MK, Zaman KU (2014) Are fluctuations in natural gas consumption per capita transitory? Evidence from time series and panel unit root tests. Energy 78(2):183-195

Sheu JB (2011) Bargaining framework for competitive green supply chains under governmental financial intervention. Transp Res Part E: Logistics and Transportation Review 47(5):573-592

Song F, Zheng X (2012) What drives the change in China's energy intensity: combining decomposition analysis and econometric analysis at the provincial level. Energy Policy 51:445-453

Stern DI, Common MS, Barbier EB (2005) Economic growth and environmental degradation: the Environmental Kuznets Curve and sustainable development. World Dev 24(7):1151-1160 
Tang X, McLellan BC, Snowden S, Zhang B et al (2015) Dilemmas for China: energy, economy and environment. Sustainability 7:5508 5520

Tiwari AK, Mutascu M, Andries AM (2013) Decomposing timefrequency relationship between producer price and consumer price indices in Romania through wavelet analysis. Econ Model 31: $151-159$

Tong D, Zhang Q, Davis SJ, Liu F, Zheng B, Geng G, Xue T, Li M, Hong C, Lu Z, Streets DG, Guan D, He K (2018) Targeted emission reductions from global super-polluting power plant units. Nat Sustain 1(1):59-68

Uddin GS, Bekiros S, Ahmed A (2018) The nexus between geopolitical uncertainty and crude oil markets: an entropy-based wavelet analysis. Physica A: Statistical Mechanics and its Applications 495:30 39

Vacha L, Barunik J (2012) Energy economics co-movement of energy commodities revisited: evidence from wavelet coherence analysis. Energy Econ 34:241-247

Wang T, Lin B (2017) China's natural gas consumption peak and factors analysis: a regional perspective. J Clear Prod 142:548-564

Wang Y, Wu C (2013) Are crude oil spot and futures prices cointegrated? Not always. Econ Model 33:641-650

Wang Y, Chen B, Guan C, Zhang B (2019) Evolution of methane emissions in global supply chains during 2000-2012. Resour Conserv Recycl 150:104414

Wei W, Wu X, Li J, Jiang X, Zhang P, Zhou S, Zhu H, Liu H, Chen H, Guo J, Chen G (2018) Ultra-high voltage network induced energy cost and carbon emissions. J Clean Prod 178:276-292

Weinzettel J, Hertwich EG, Peters GP, Steen-Olsen K, Galli A (2013) Affluence drives the global displacement of land use. Glob Environ Chang 23:433-438

World Energy Council. Perspectives on grand energy transition. (2018) https:/www. worldenergy.org/wp-content/uploads/2018/05/IssuesMonitor-2018-HQ-Final.pdf. Accessed 1 May 2016

World Trade Organization (2002) Protocolon the accession of the People's Republic of China. China's Economic and Trade 1:99-107

Wu XD, Guo JL, Han MY, Chen GQ (2018) An overview of arable land use for the world economy: from source to sink via the global supply chain. Land Use Policy 76:201-214
Wu CF, Wang CM, Chang TY, Yuan CC (2019) The nexus of electricity and economic growth in major economies: The United States-IndiaChina triangle. Energy 188:116006

Xia X, Chen B, Wu X, Hu Y et al (2017) Coal use for world economy: provision and transfer network by multi-region input-output analysis. J Clean Prod 143:125-144

Xiao CM, Wang Z, Shi WF et al (2018) Sectoral energy-environmental efficiency and its influencing factors in China: Based on S-U-SBM model and panel regression model. J Clear Prod 182:545-552

Xie W, Sheng PF, Guo XH (2015) Coal, oil, or clean energy: which contributes most to the low energy efficiency in China? Util Policy 35:67-71

Yang L (2019) Connectedness of economic policy uncertainty and oil price shocks in a time domain perspective. Energy Econ 80:219-233

You W, Guo Y, Zhu H, Tang Y (2017) Oil price shocks, economic policy uncertainty and industry stock returns in China: asymmetric effects with quantile regression. Energy Econ 68:1-18

Zhang X, Yousaf HAU (2020) Green supply chain coordination considering government intervention, green investment, and customer green preferences in the petroleum industry. J Clean Prod 246: 118984

Zhang XJ, Sun JY, Wang YQ et al (2013) Thinking about the cause and governance of fog-haze in China. Chin Sci Bull 58(13):1178-1187

Zhang H, Li L, Zhou D, Zhou P (2014) Political connections, government subsidies and firm financial performance: evidence from renewable energy manufacturing in China. Renew Energy 63:330-336

Zhang C, Zhong L, Wang J (2018) Decoupling between water use and thermoelectric power generation growth in China. Nat Energy 3: 792-799

Zhang YY, Chen QT, Chen B, Liu JF (2020) Identifying hotspots of sectors and supply chain paths for electricity conservation in China. J Clean Prod 251:119653

Zhou S, Wei W, Chen L, Zhang Z et al (2019) Impact of a coal-fired power plant shutdown campaign on heavy metal emissions in China. Environ Sci Technol 53:14063-14069

Publisher's note Springer Nature remains neutral with regard to jurisdictional claims in published maps and institutional affiliations. 